\title{
EVALUATING STRATEGIC EDUCATIONAL PLANNING PRACTICES AT THE MINISTRY OF EDUCATION IN THE SULTANATE OF OMAN

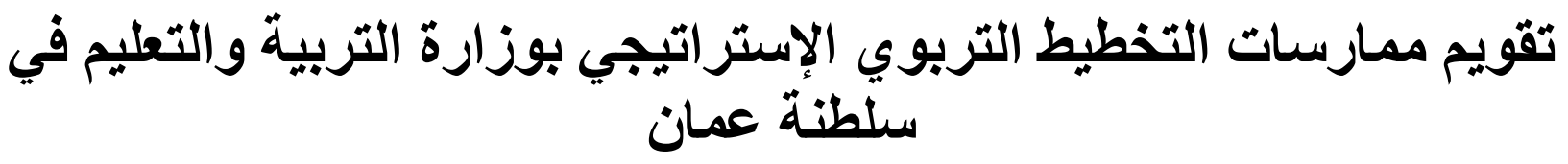

\author{
سعيد بن خلفان بن سعيد الرواحي \\ Said Khalfan Said ALrawahi ${ }^{1 *}$, Ismaiel Hassanein Ahmed ${ }^{2}$, Mohamed Johdi Saleh ${ }^{3}$ \\ ${ }^{1}$ Ph.D. Candidate at Kulliyyah of Education, International Islamic University Malaysia (IIUM), \\ s.rawahi@hotmail.com \\ ${ }^{2}$ Prof. Dr. at the Faculty of Education, International Islamic University Malaysia (IIUM), \\ Tolib52@iium.edu.my \\ ${ }^{3}$ Dr., Senior lecture at Kulliyyah of Education, International Islamic University Malaysia (IIUM), \\ johdi@iium.edu.my \\ ${ }^{*}$ Corresponding Author
}

\begin{abstract}
The current study aimed to identify the reality of planning practices for workers in educational planning agencies in the Ministry of Education in the Sultanate of Oman. The problem arose out of the existence of many aspects of deficiency and shortcomings in the exercise of the planning tasks assigned to them in these bodies, in addition to the presence of other problems experienced by these devices, which limit the efficiency and effectiveness of workers to exercise the tasks assigned to them. To achieve the objectives of the study, a questionnaire was formed consisting of (50) items, which were classified according to four axes represented by planning practices for workers in educational planning agencies, namely: tasks of educational planning agencies, administrative organization, planning cadres, educational information. The study sample consisted of (208) individuals with positions: department manager, deputy director, head of department, and a technical member in the planning departments of the Ministry and educational governorates in the Sultanate of Oman, and statistical processing of data was carried out using arithmetic averages, standard deviations and rank. The results of the study showed: The planning practices of workers in educational planning agencies in the four fields of study: tasks of planning organs, administrative organization, planning cadres, educational information were of a moderate degree.
\end{abstract}

Keywords: evaluation, planning, educational.

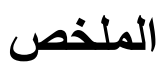

هدفت الدراسة الحالية إلى التعرف على واقع الممارسات التخطيطية للعاملين بأجهزة التخطيط التربوي في وزارة التربية والتعليم بسلطنة عمان. برزتُ المشكلة بوجود العديد من جوانب النقص 


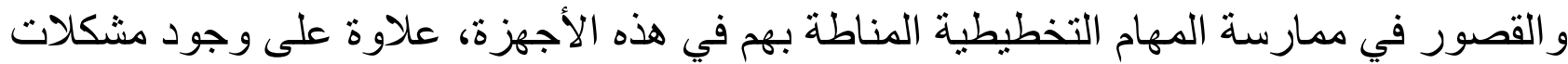

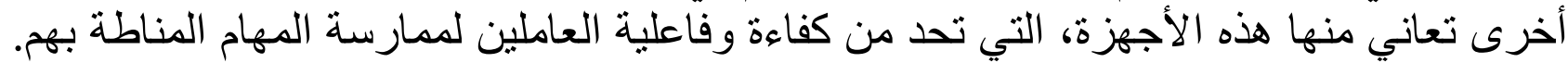

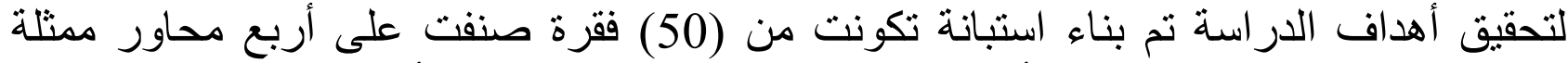

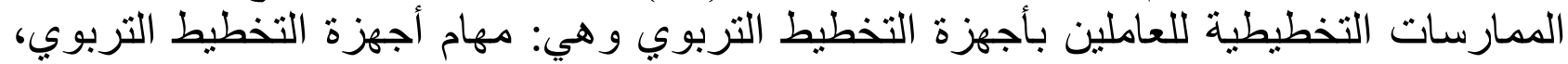

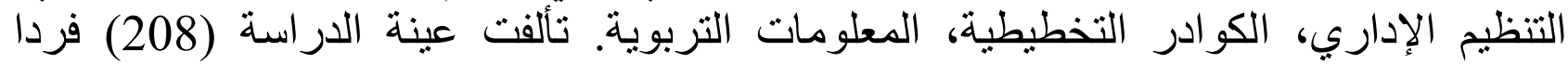

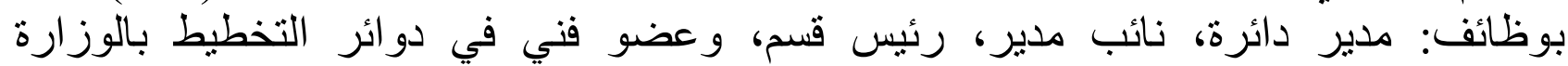

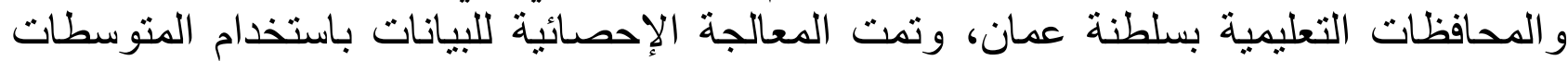

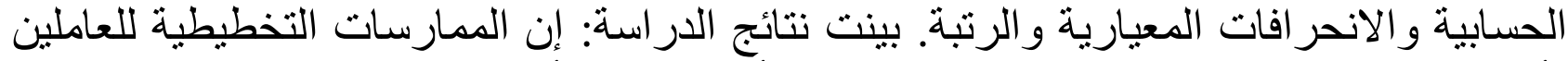

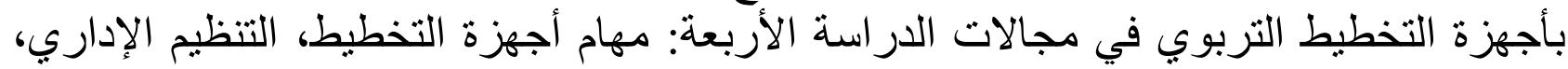
الكو ادر التخطيطية، المعلومات التربوية كانت بدرجة متوسطة. كلمات مفتاحية: تقويم، التخطيط، التربوي.

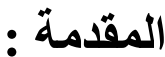

نظرا إلى التطور السريع والمتلاحق في مجالات الحياة التربوية و السياسية والاجتماعية

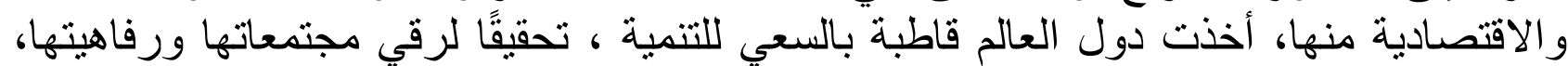

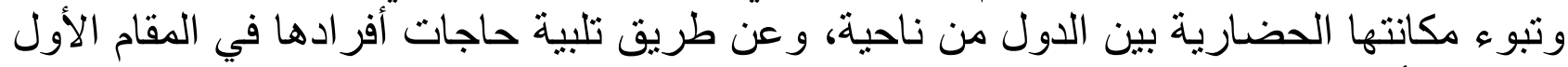

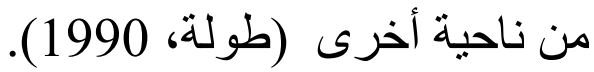

و هناك مجمو عة من المعايير لتقويم التخطبط التربوي وأجهزته و أقسامه، منها ما يتعلق بفترة ماقبل

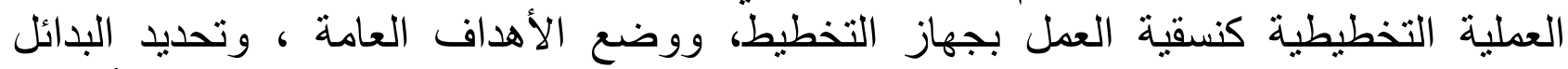

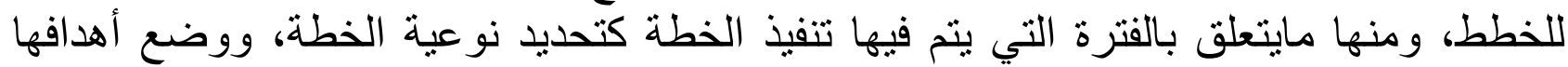

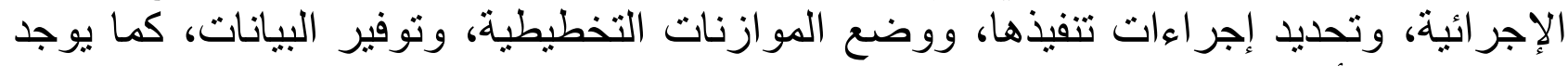

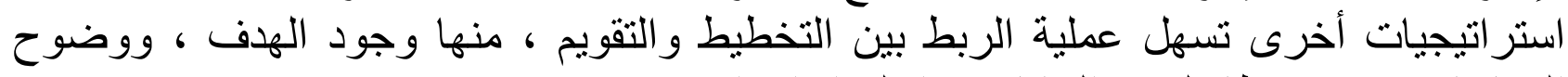
السياسات، وتوفر نظام لجمع البيانات، و الالتز ام الإداري التين (حجي، 1992).

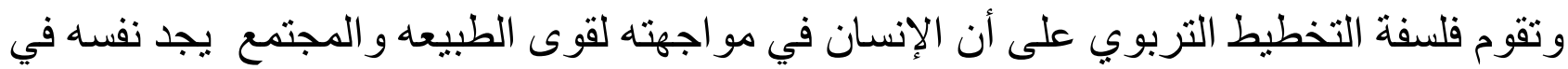

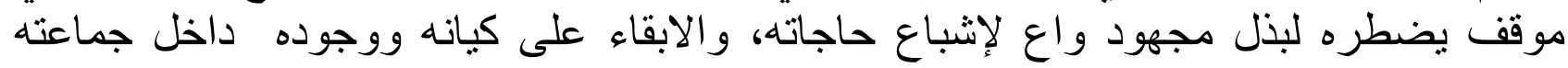

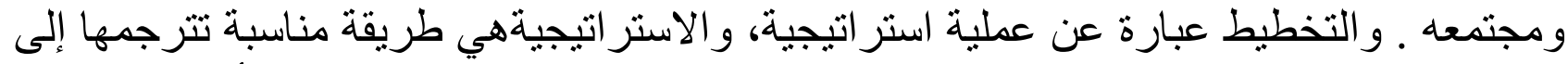

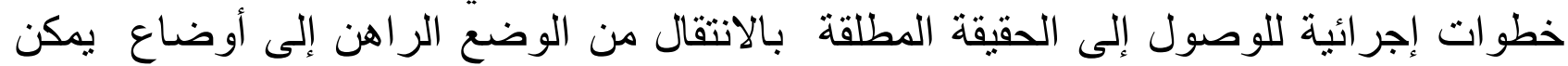

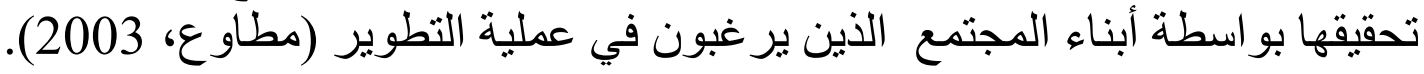

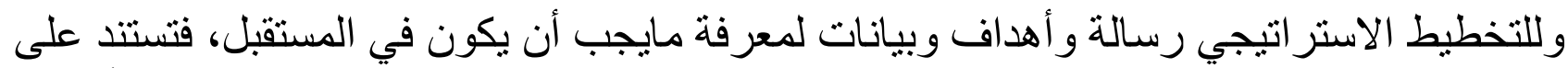

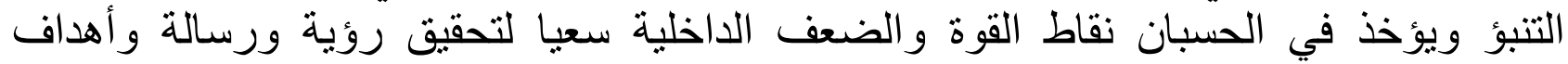

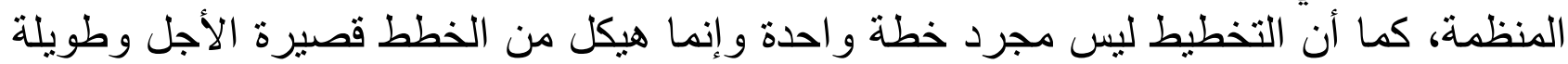

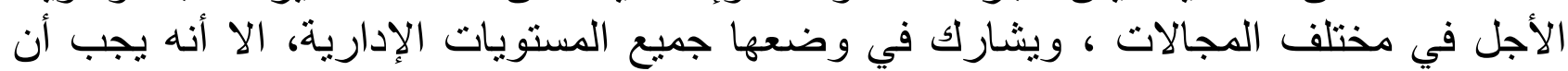
يكون لديها مقومات وعناصر أساسية تحدد من كفاءة التخطيط ومتطلباته فيجب التبن التفكير فيها فبل التبل 


\section{البدء في التخطيط (ماهر، 2009) .}

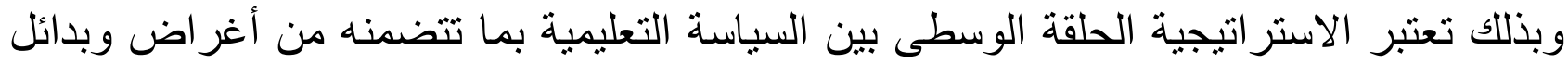

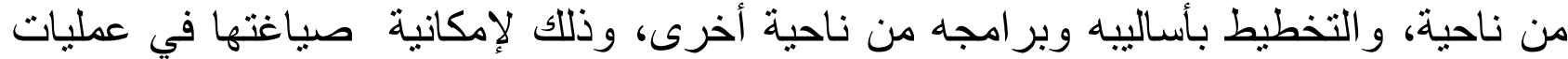

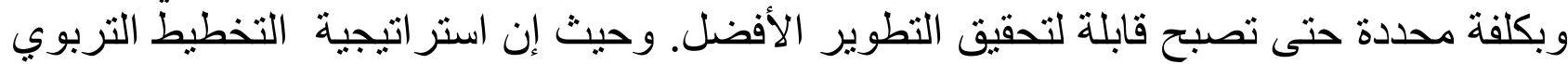

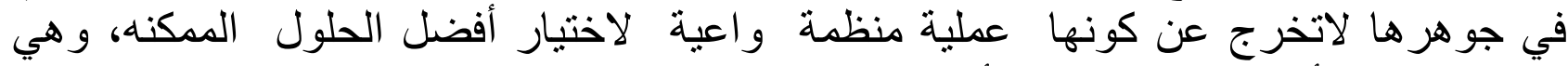
عملية ترتيب الأوليات للوصول عن إلى أهداف تعليمية معينة (غيداء عبدالله، 2007).

انطلاقا من أهمية التخطيط فقد اعتمدته سلطنة عمان منذ عام 1970م؛ لتحقيق الرقي والتقدم التام

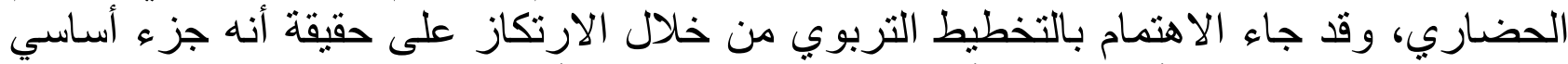

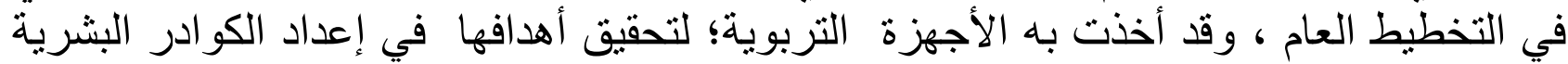

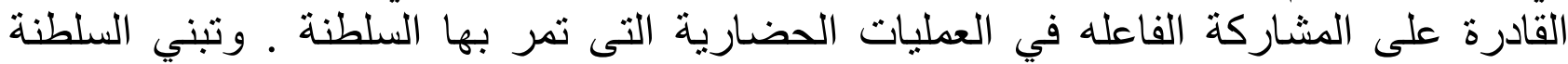

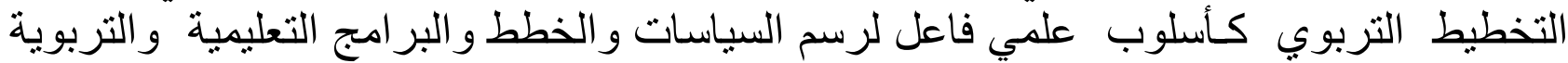

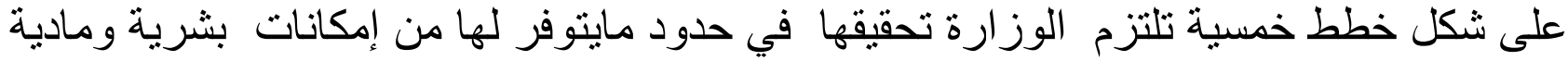

(اللزامي، 2003).

وتتولى عملية التخطيط التربوي رسم السياسات التربوية والتعليمية ، ومعالجة المشكلات

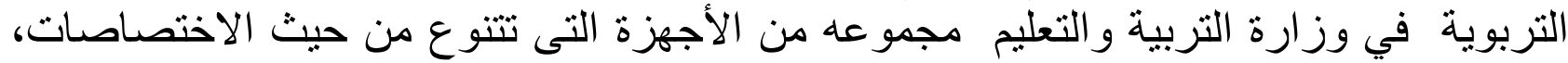

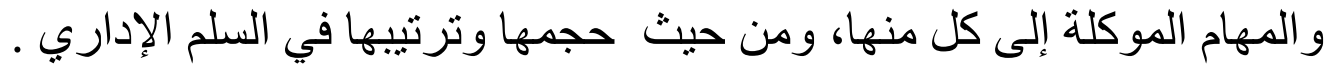

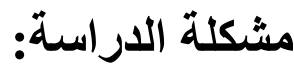

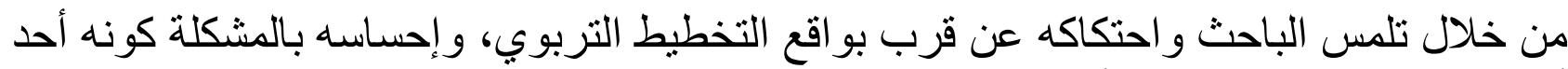

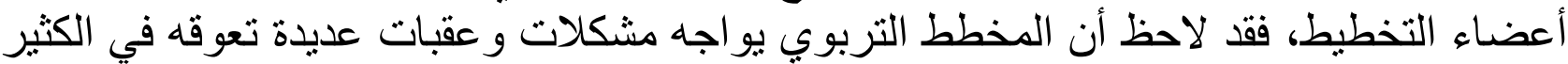

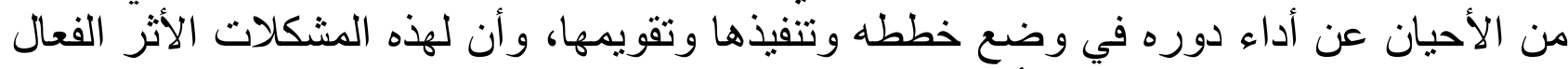

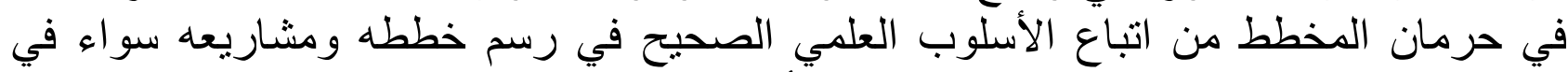
ديوان عام وزارة التربية والتعليم بسلطنة عمان، أو المديريات التابعة لهاب لها في المحافظات المختلفة.

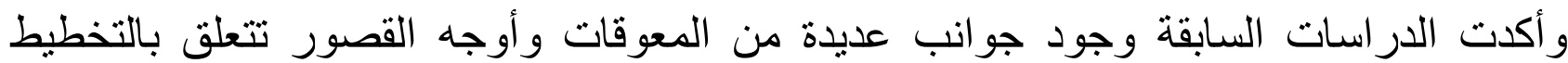

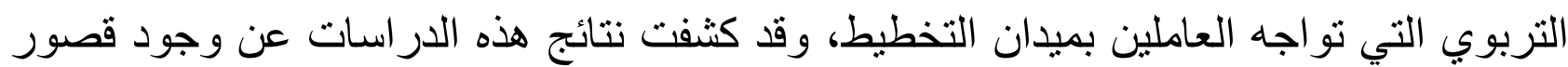

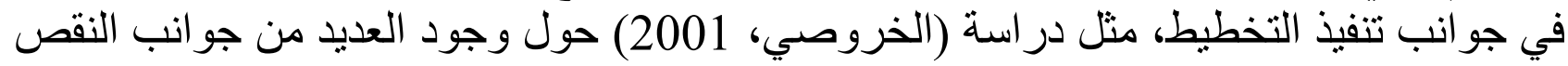

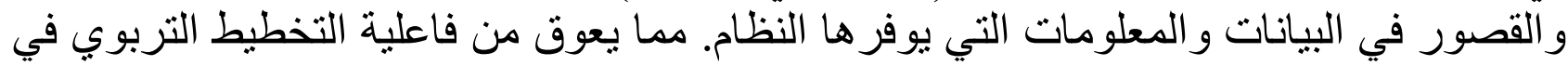
تحقيق التنمية التربوية في مجال نشر التعليم وتجويده بالسلطنة.

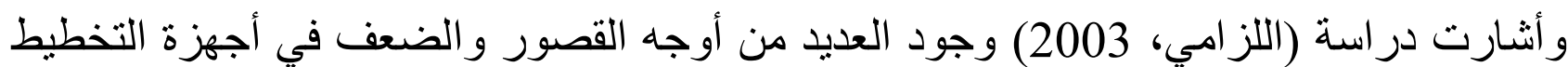

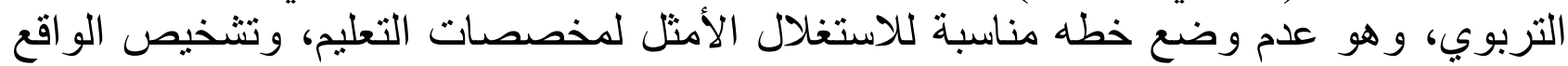

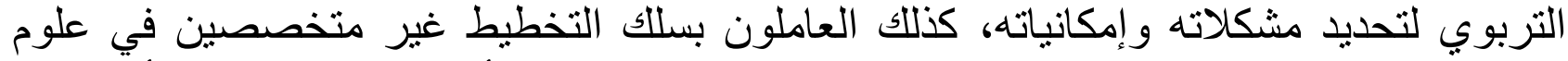

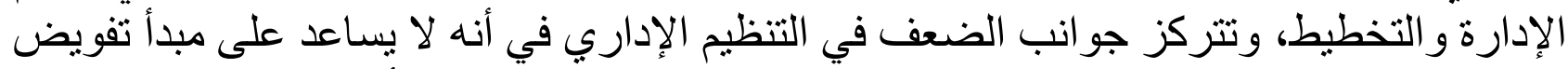

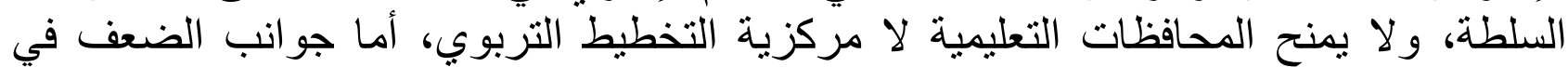

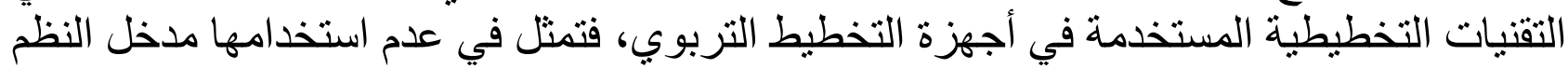

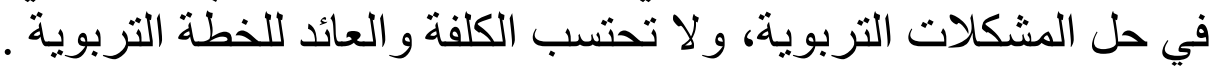




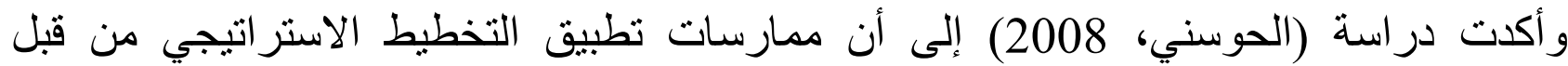

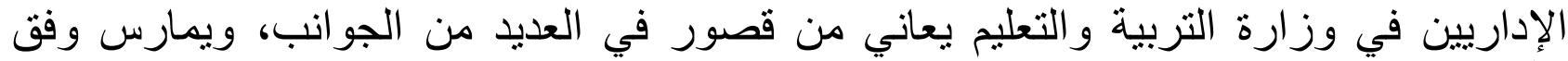

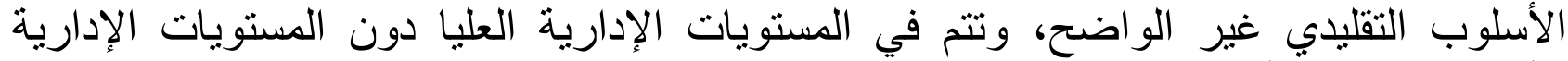

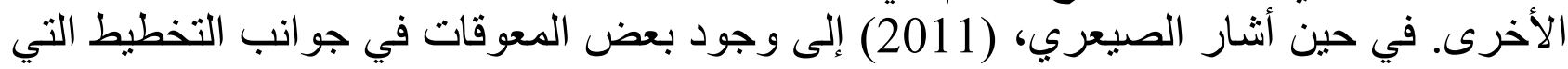

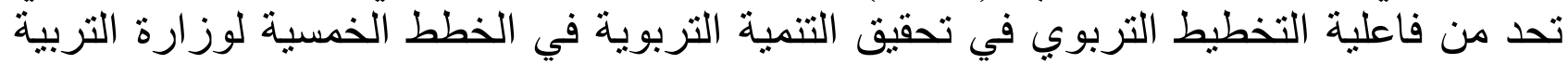

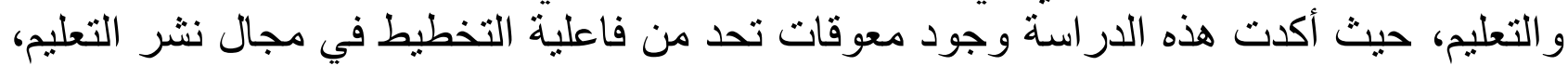
وكذلك في مجال تجويد التعليم

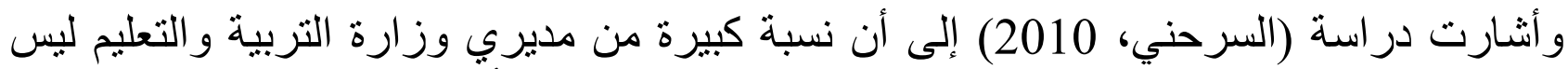

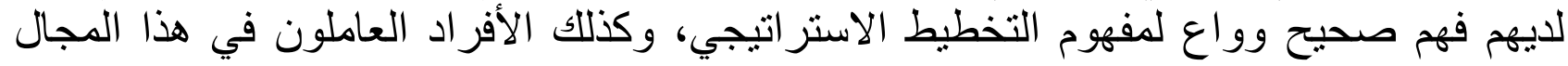
التخطيطي وكيفية وضع الخطط المستقبلية وتشخيص الو اقع الحالي للتخطيط.

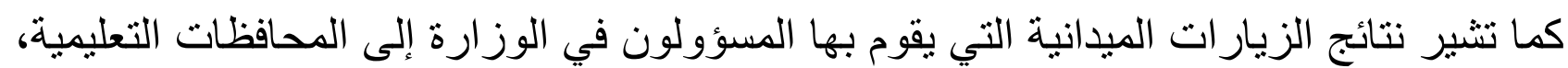

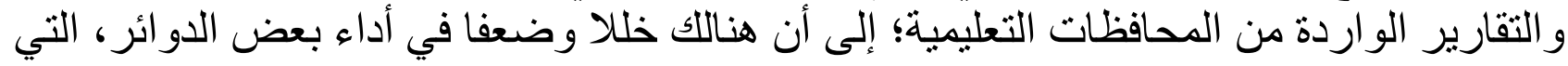

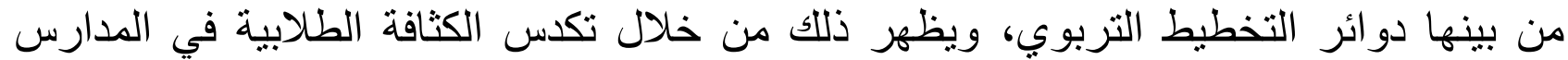
و الصفوف، وقلة الكادر الإداري والنقص في الهيئات الإدارية (وزارة التربية و التعليم ، 2001).

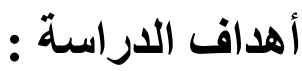

أ. التعرف على و اقع التخطيط التربوي في وزارة التربية والتعليم بسلطنة عُمان. ب. تقويم الممارسات التخطيطية بأجزةة التخطيط التربوي في وزارة التربية و التعليم بسلطنة عمان. (- مان.

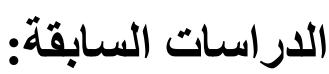
دراسة الكردي، (2010) بعنو ان درجة تطبيق التخطيط في مديريات التربية و التعليم في محافظة

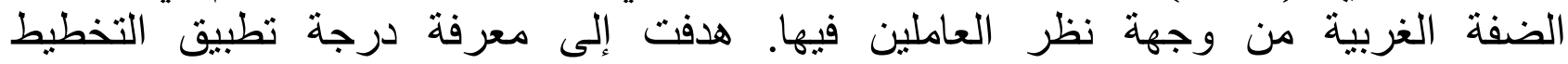

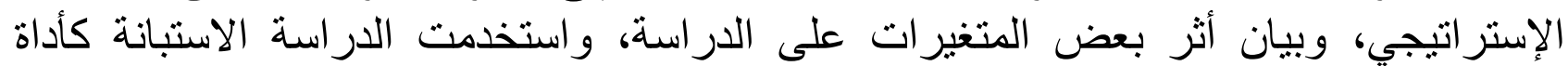

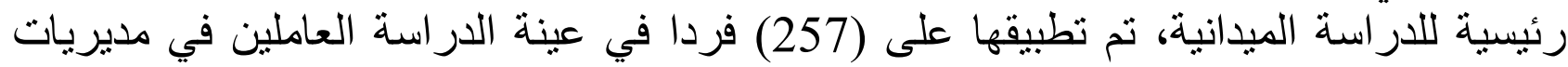

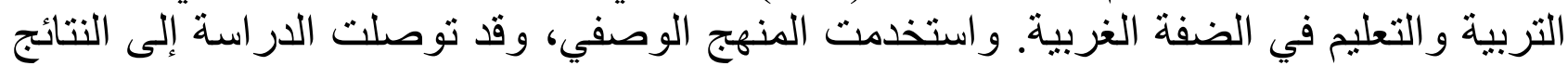

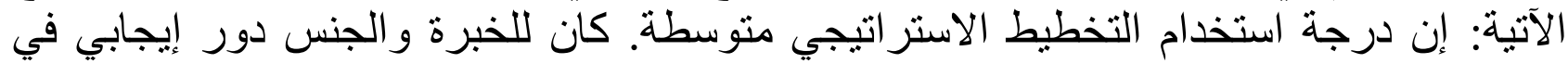

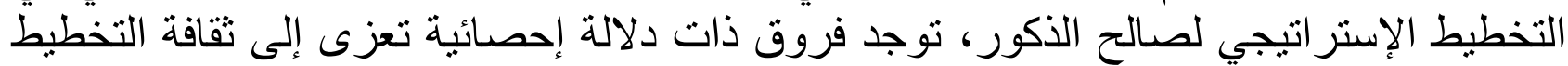
الإستر اتيجي وملائمة الأهداف.

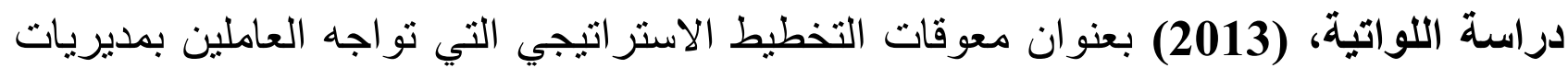

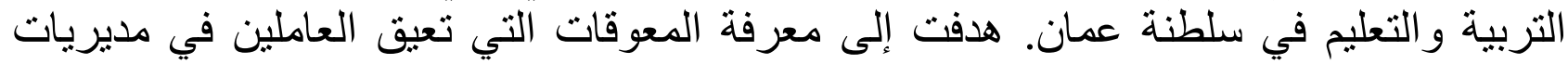

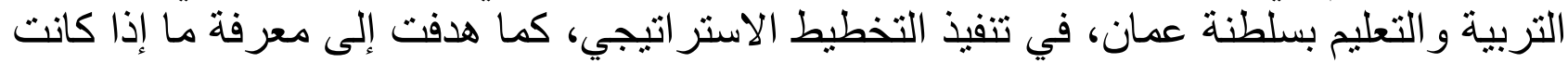

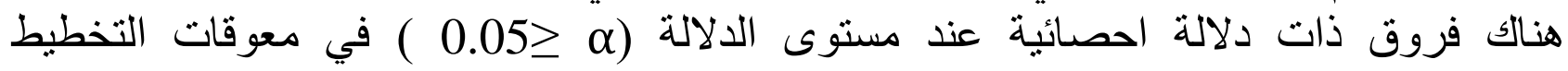

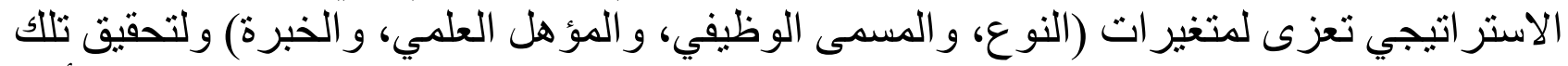

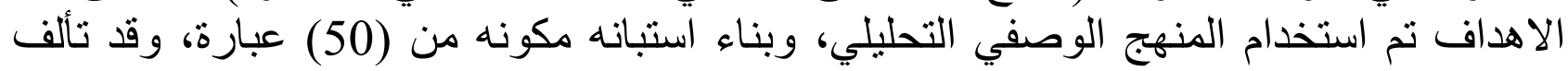
مجتمع الدراسة من (72) فردا، وتوصلت الدراسة إلى: وجود معوقات كبيرة في تنفيذ التخطيط وناء 
الاستر اتيجي. لاتوجد فروق ذات دلالة احصائية عند مستوى الدلالة تعزى لمتغيرات (النوع،

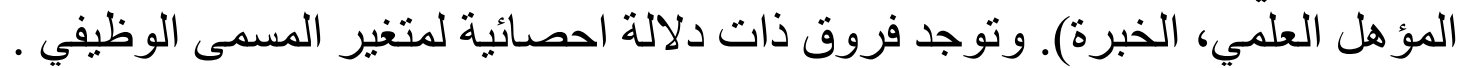

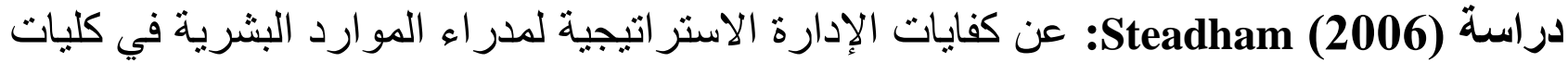

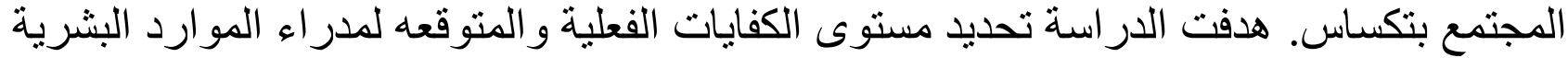

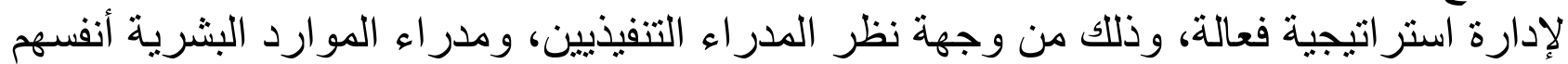

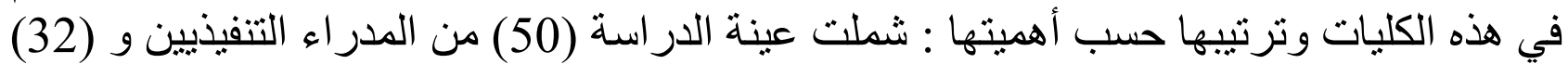

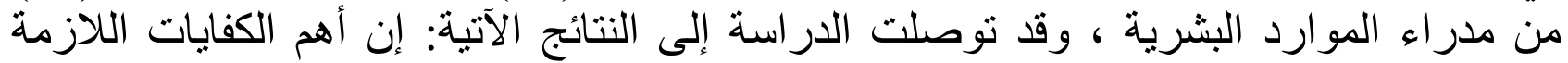

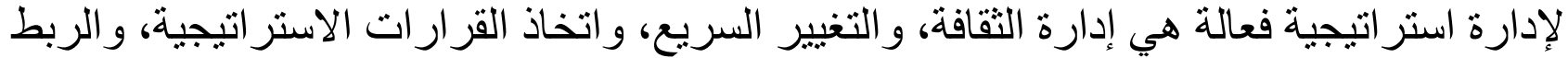

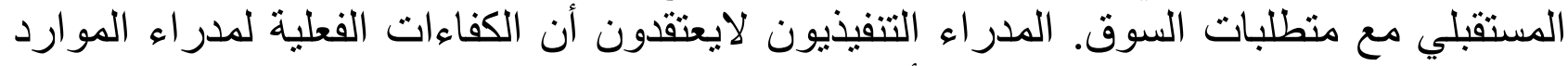

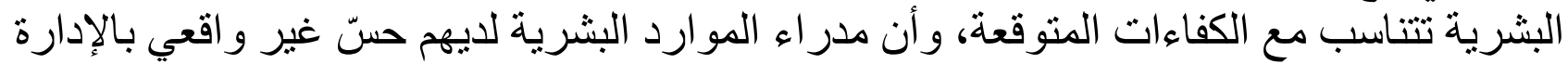

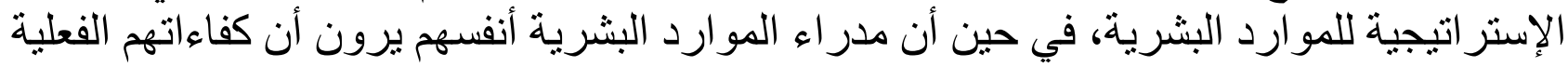

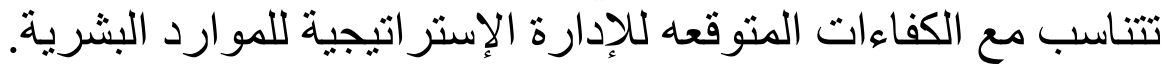

دراسة هاني، وهبة (2008)؛ حول واقع الإدارة الاستر اتيجية في الجامعات الفلسطينية في

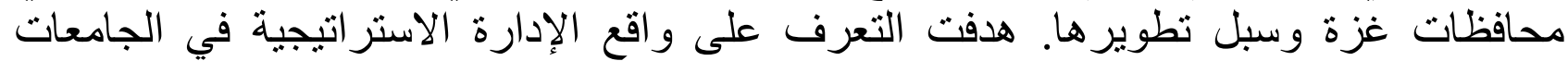

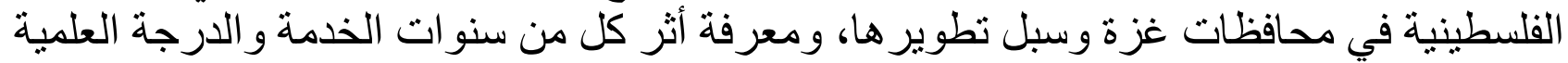

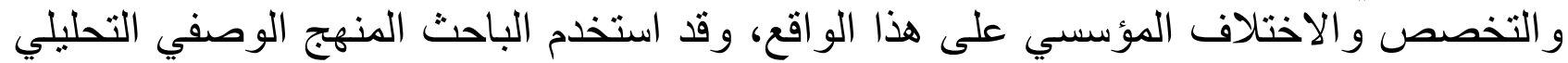

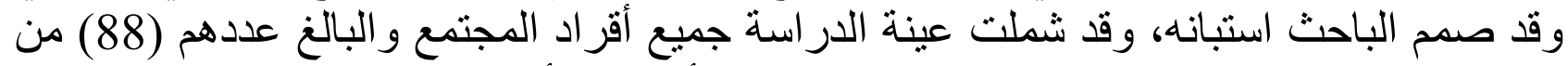

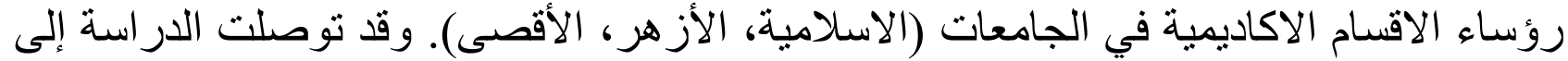

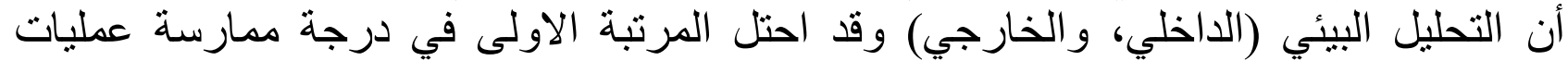

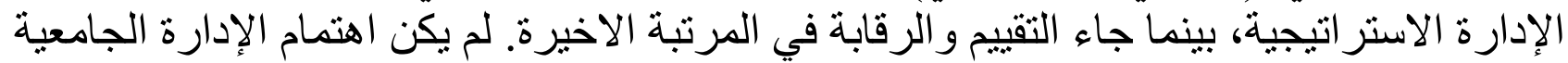

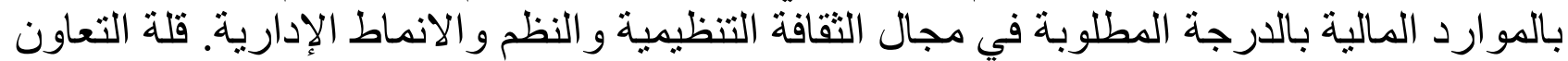

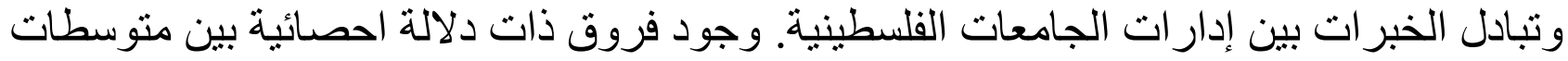

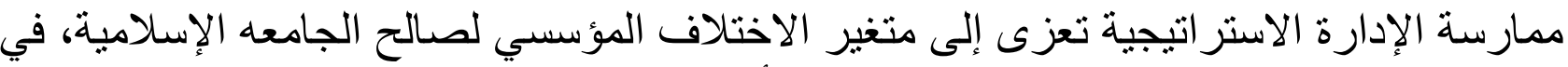
حين لاتوجد فروق تعزى إلى متغير ات الدئ الدر استة الأخرى.

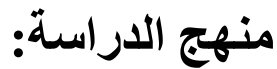

استخدم الباحث المنهج الوصفي التحليلي وهو المنهج الذي يدرس ظاهره أو حدثا أو قضية

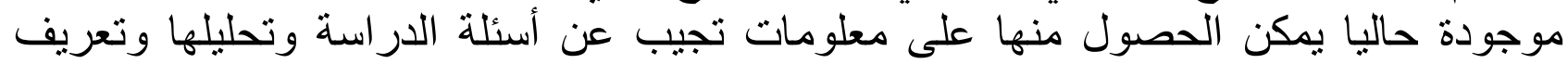
العلاقات بين مكون هاتها دون تدخل الباحث في فيها.

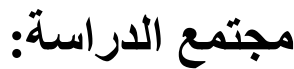

تكون مجتمع الدراسة من العاملين بالتخطيط التربوي في دائرتي التخطيط و الاحتياجات ودائرة

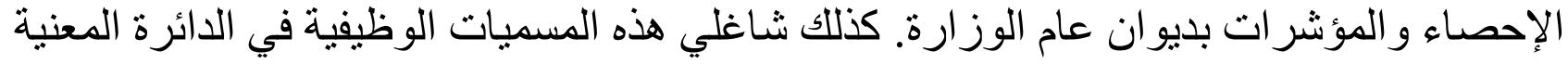

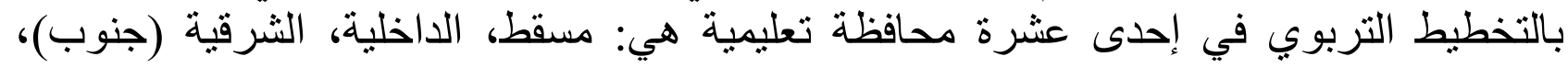

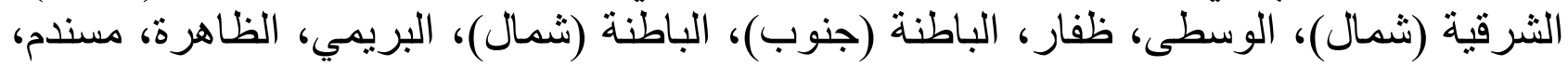

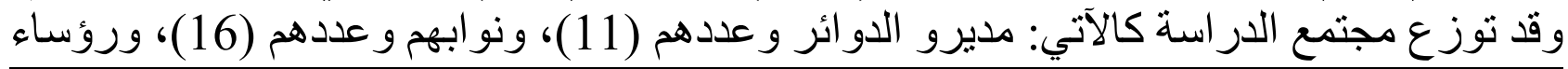




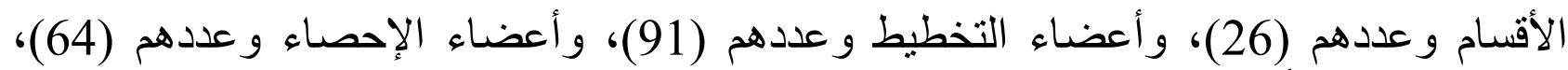

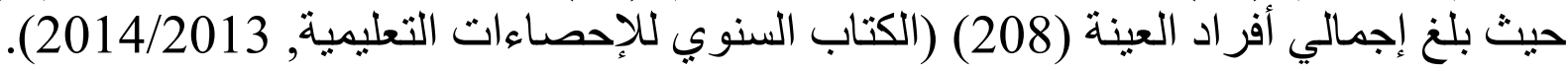

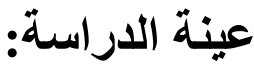
شملتن عينة الدر اسة الأساسية على عدد (137) فردا، تم اختيار هم عشو ائيا من مجتمع الدراسة،

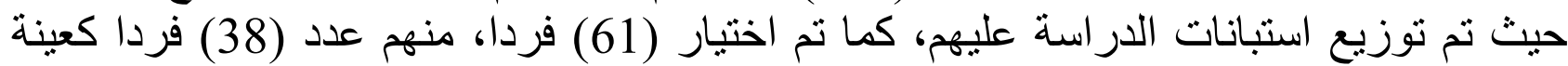
استطلاعية أولى و(33) فردا كعينة استطلاعية ثنانية للتبات.

صدق المحتوى (المضمون): تم حساب صدق المحتوى بعرض استمارة الاستبيان المقترحة لتطوير التخطيط التربوي بوزارة التربية والتعليم في سلطنة عمان على التى الخبراء بلغ بلغ عددهم (14)

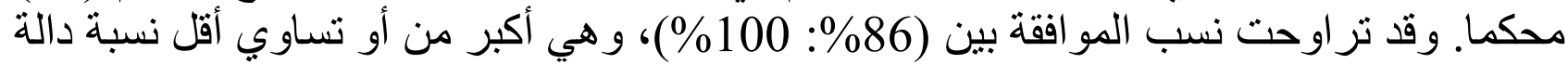
و المستخرجة من اختبار معنوية النسب و البالغة (80\%) و (80\% عليه تقبل جميع محاور الاستبيان.

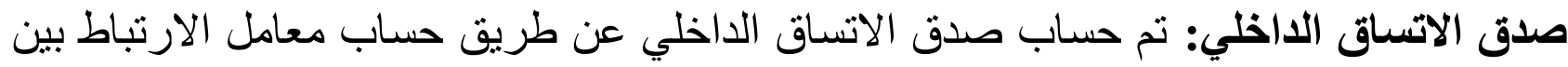

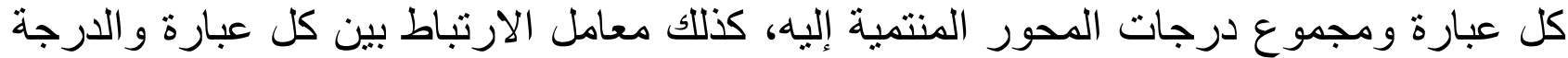
الكلية للاستبيان ككل، ثم معامل الارتباط بين مجموع درجات المحور و الدرجة الكلية للئلاستبيان. جدول (1) معاملات ارتباط مجموع درجات كل محور مع الدرجة الكلية لاستمارة استبيان

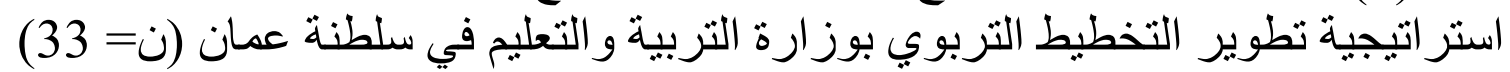

\begin{tabular}{|c|c|c|c|c|c|}
\hline ارأباط العبارة مع الكلية & الارجة الكلية للمحور & المعياري & الحستبي & المحاور & r \\
\hline 0,79 & 0,80 & 0,81 & 1,91 & مهام أجهزة التخطيط التربوي & 1 \\
\hline 0,81 & 0,76 & 0,85 & 2,18 & التخطيط التربوي الإداري لأجهزة & 2 \\
\hline 0,71 & 0,81 & 1,11 & 2,31 & أجهزة التخطيط التربوية العاملة في & 3 \\
\hline 0,61 & 0,70 & 0,82 & 1,90 & المعلومات التربوية & 4 \\
\hline
\end{tabular}

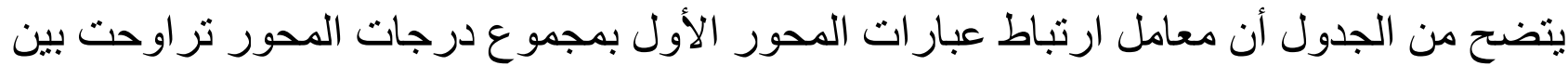

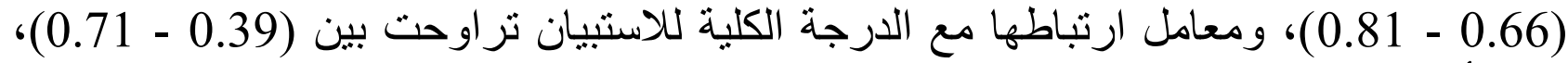
و هي أكبر من قيمة (ر) الجدولية مما يشير إلى اتساق هذه العبار العبار ات مع المحور الذي تنتمي إليه ومع الاستبيان ككل.

الثبات: قام الباحث باستخر اج معامل ألفا ومعامل التجزئة النصفية لحساب ثبات الاستمارة

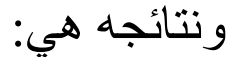
جدول (2) قيم معاملات ألفا والتجزئة النصفية لمحاور الاستبيان ألفا كرو نباخ التجزئة النصفية المحاور 
IJASOS- International E-Journal of Advances in Social Sciences, Vol. VI, Issue 17, August 2020

\begin{tabular}{|c|c|c|c|}
\hline 0,89 & 0,90 & مهام أجهزة التخطيط التربوي & 1 \\
\hline 0,86 & 0,89 & التنظيم الإداري لأجهزة التخطيط التربوي & 2 \\
\hline 0,89 & 0,90 & التربوادر التخطيطية العاملة في أجززة التخطيط & 3 \\
\hline 0,94 & 0,95 & المعلومات التربوية & 4 \\
\hline 0,73 & 0,73 & الاستبيان ككل & \\
\hline
\end{tabular}

يوضح الجدول رقم (2) معامل ألفا كرو نباخ ومعامل التجزئة النصفية لمحاور الاستبيان

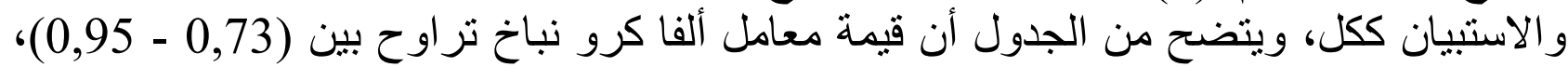

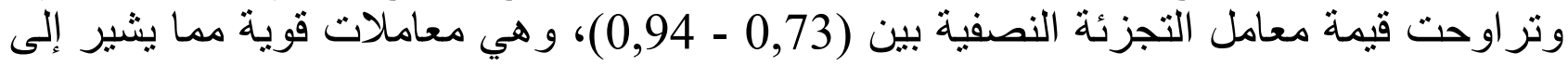
تبات الاستبيان. المعالجات الإحصائية: اثتنمل الأسلوب الإحصائي المستخدم في الدراسة ما يلي:

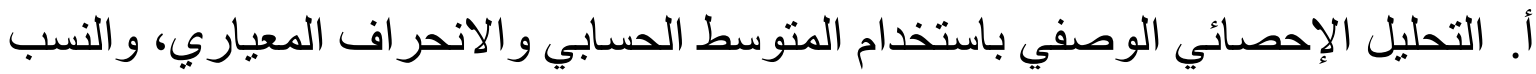

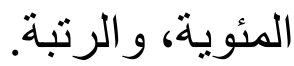
ب. ب. معاملات الارتباط.

LSD ت ت اختبار

وذللك باستخدام برنامجي: SPSS و عرض النتائج ومناقشتها عرض النتائج المتعلقة بالسؤال الأول والذي ينص علئه على: (ما واقع التخطيط التربوي في وزارة

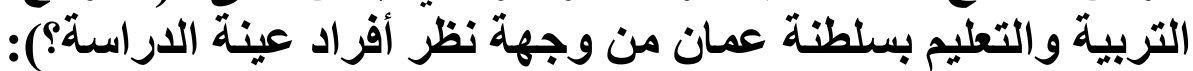

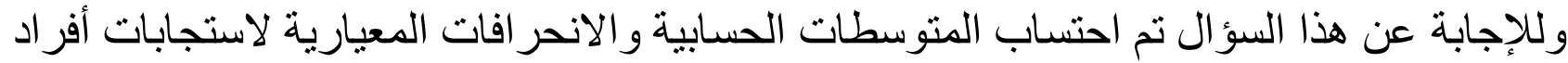

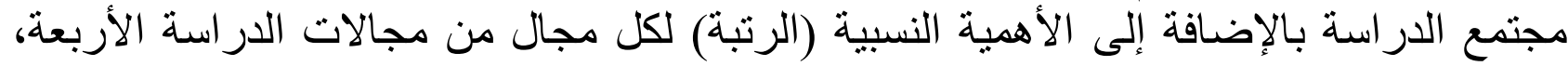

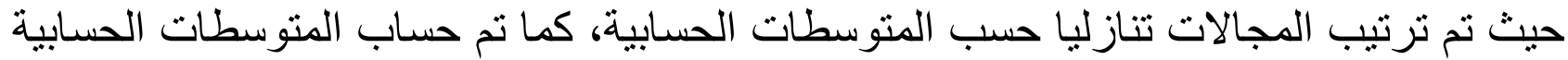

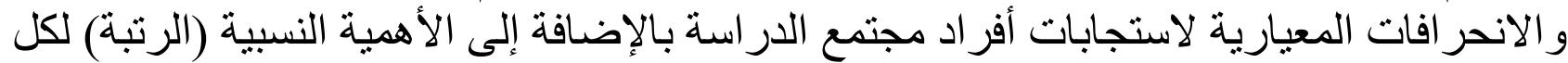

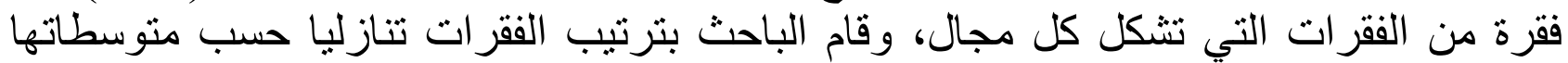

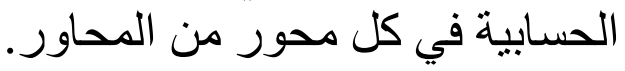
وقد اعتمد الباحث في الحكم على درجة الممارسات التخطيطية للعملين بأجهزة التخطيط التربوي

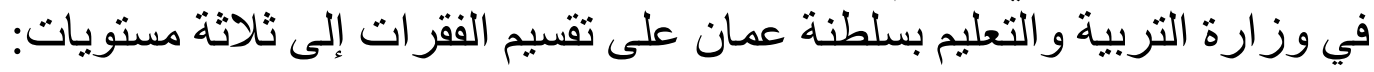

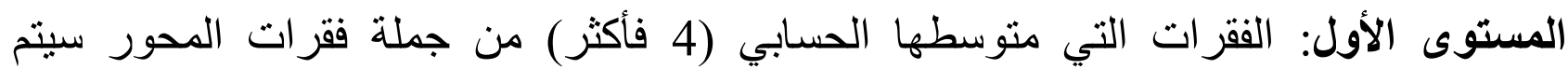
اعتبار ها جانب قوة في أجهزة التخطبط التربوي. المستوى الثاني: الفقرات التي منوسطها الحسابي (أقل من 2) من جملة فقرات المحور سيتم 
اعتبار ها جانب ضعف في أجززة التخطيط التربوي. المستوى الثالث: الفقرات التي متوسطها الحسابي (يقع بين 2 و أقل من 4) من جملة فقرات المحور فإنها تقع في المستوى المنوسط. ويبين الجدول رقم (3) المتوسطات الحسابية والانحر افات المعيارية والأهمية النسبية(الرتبة)

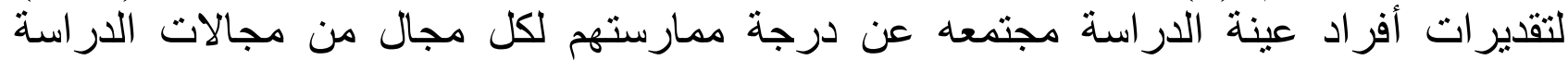
الأربعة.

جدول (3) تقدير ات أفر اد عينة الدر اسة مجتمعه عن المجالات التخطيطية مرنبة تنازليا

\begin{tabular}{|c|c|c|c|c|c|}
\hline الممارسة & الانحرياف & الحسابي & مجالات التخطيط & الأهمية النسبية & الاستبالنة في \\
\hline متوسطة & 0,46 & 3,86 & مهام أجهزة & 1 & 1 \\
\hline متوسطة & 0,52 & 3,58 & المعلومات التربوية & 2 & 4 \\
\hline متوسطة & 0,58 & 3,43 & الكو ادر التخطيطية & 3 & 3 \\
\hline متوسطة & 0,41 & 3,33 & التنظيم الإداري & 4 & 2 \\
\hline
\end{tabular}

ويتضح من الجدول رقم (3)، بأن المتوسطات الحسابية للمجالات التخطيطية الأربعة قد نراوحت بين $(3,33)$ و $(3,86)$ و هذا يعني أن جميع المجالات المتعلقة بجو انب التخطبط تمارس بدرجة التبة متوسطة.

\section{النتائج حسب كل مجال}

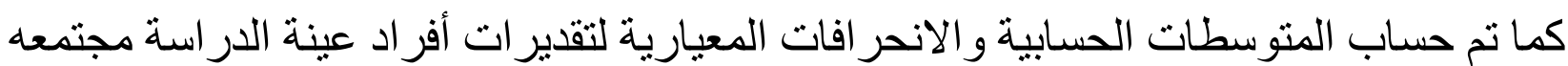

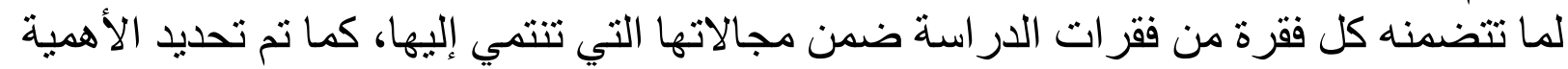

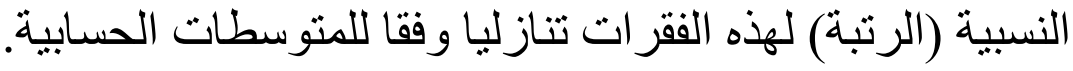

\section{المجال الأول: مهام أجهزة التخطيط التربوي}

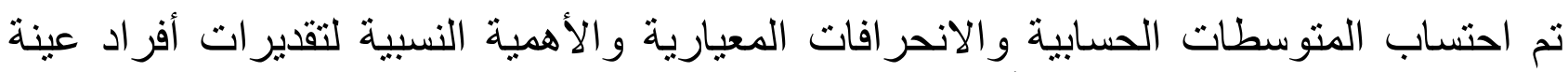

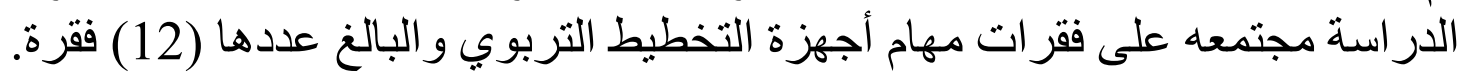
جدول (4) تقدير ات أفر اد عينة الدر اسة مجتمعه على فقرات مهام أجززة التخطيط التربوي

\begin{tabular}{|c|c|c|c|c|c|}
\hline الممارسة & 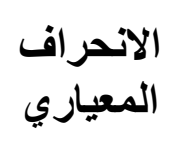 & الحستب الحتي & 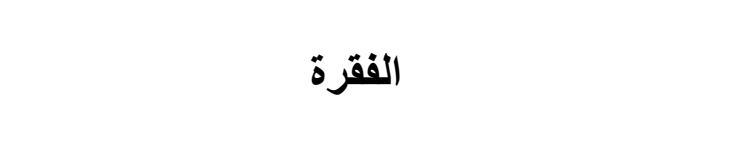 & الرتبة & 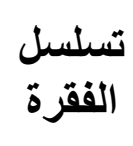 \\
\hline 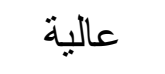 & 0,70 & 4.73 & إعداد بيان بالاحتياجات من الهيئات التدريسية & 1 & 8 \\
\hline 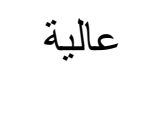 & 0,54 & 4,61 & للأبنية الاحتياجات من أعمال الإضافات اللازمة & 2 & 7 \\
\hline 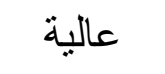 & 0,58 & 4,60 & حصر احتياج المحافظات من المباني المدرسية & 3 & 4 \\
\hline
\end{tabular}


IJASOS- International E-Journal of Advances in Social Sciences, Vol. VI, Issue 17, August 2020

\begin{tabular}{|c|c|c|c|c|c|}
\hline عالية & 0.75 & 4,37 & المشاركة في بناء الخطة الدر اسية & 4 & 11 \\
\hline عالية & 0,91 & 4.06 & مر اجعة وتحليل البيانات الإحصائية التربوية & 5 & 5 \\
\hline متوسطة & 1,49 & 3,89 & تحديد احتياجات الوزارة من مختلف الوظائف & 6 & 3 \\
\hline متوسطة & 1,02 & 3,73 & إعداد الخطة الخمسية التربوية & 7 & 1 \\
\hline متوسطة & 0,63 & 3,66 & جمع البيانات الإحصائية لوضع الخطط التربوية & 8 & 12 \\
\hline 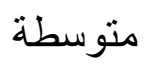 & 1,09 & 3,48 & المساهمة في نشر التعليم وإتاحته للجميع & 9 & 6 \\
\hline 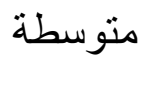 & 0,86 & 3,27 & وضحافظة تصور للخريطة المدرسية على مستوى & 10 & 2 \\
\hline 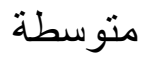 & 1,15 & 3,19 & التقويم المستمر للخطط التربوية & 11 & 9 \\
\hline 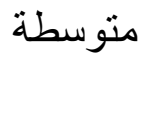 & 1,20 & 3,07 & التربية المشاركة في وضع الأهداف الخاصة بفلسفة & 12 & 10 \\
\hline
\end{tabular}

من خلال الجدول (4) تشير النتائج إلى: وجود خمس فقرات نرات اوحت منوسطاتها الحسابية بين

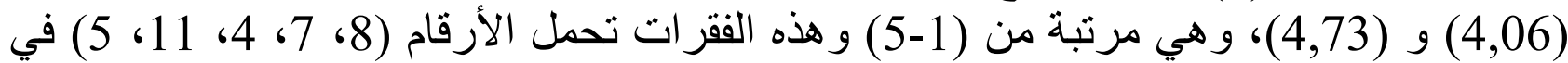

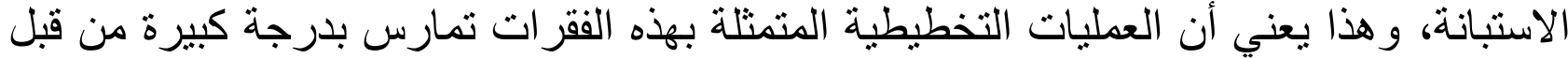
العاملين بأجهزة التخطيط التربوي من وجهة نظر أفر النئ العينة.

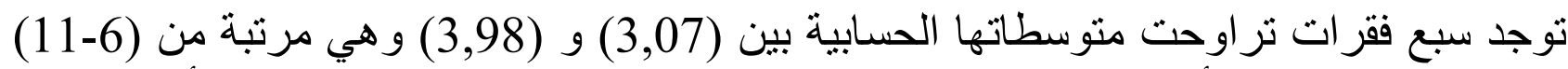

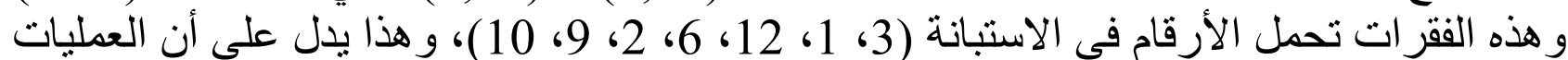
التخطيطية المتمثلة بهذه الفقرات تمارس بدرجة متوسطة من قبل العاملين بأجهزة التخطيط

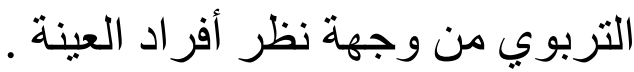

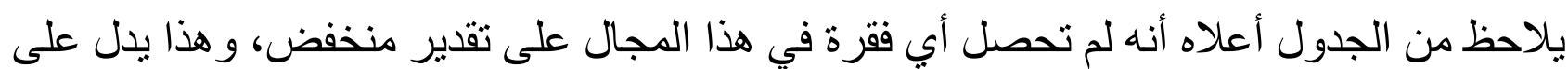

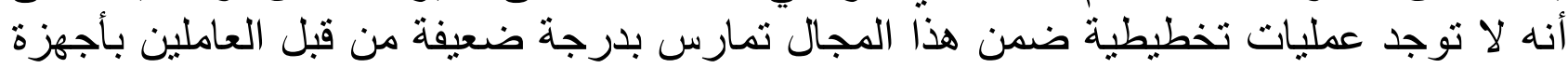
التخطيط التربوي من وجهة نظر أفر اد عينة الدر اسة.

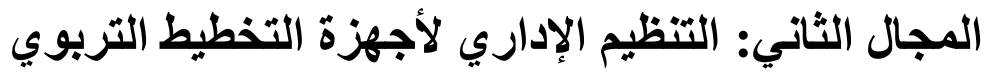
يبين الجدول (5) المتوسطات الحسابية والانحرافات المعيارية والأهمية النسبية (الرتبة)

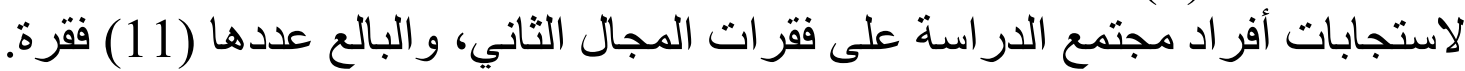

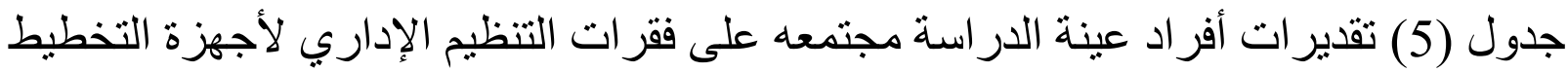
التربوي

\begin{tabular}{|c|c|c|c|c|c|}
\hline الممارسة درة & الالمعرافي & المستوسط & الفقرة & الرتبة & تسلسل \\
\hline
\end{tabular}


IJASOS- International E-Journal of Advances in Social Sciences, Vol. VI, Issue 17, August 2020

\begin{tabular}{|c|c|c|c|c|c|}
\hline عالية & 0,61 & 4,08 & و المحدافظات علاقة العمل بين ديو ان عام الوزارة & 1 & 4 \\
\hline متوسطة & 0,75 & 3,79 & تتضح فيه الاختصاصات الإدارية والفنية للأقسام & 2 & 6 \\
\hline متوسطة & 0,81 & 3,66 & المتيح التنسيق مع الجهات التخطيطية الأخرى في & 3 & 10 \\
\hline متوسطة & 0,84 & 3,52 & يتبع مبدأ التشاور في اتخاذ القر ار ات التربوية & 4 & 1 \\
\hline متوسطة & 0,97 & 3,45 & يتم فيه توصيف مهام الوظائف الإدارية والفنية & 5 & 11 \\
\hline متوسطة & 0,81 & 3,41 & يمنلك آلية و اضحة للمر اقبة وقياس الأداء & 6 & 5 \\
\hline متوسطة & 0.93 & 3,41 & العلمية العاملين في أقسامه المختلفة وفق تخصصاتهم & 6 & 3 \\
\hline متوسطة & 0.78 & 3,34 & ير اعى الكفاءة في إسناد الوظائف للعاملين فيه & 7 & 2 \\
\hline متوسطة & 0.94 & 3,06 & بمتلك استر اتيجية لتطوير أجهزة التخطيط التربوي & 8 & 9 \\
\hline متوسطة & 0,86 & 2,64 & يساعد على مبدأ تفويض السلطة & 9 & 8 \\
\hline متوسطة & 0,73 & 2,28 & تتمتع باللامركزية في التخطيط & 10 & 7 \\
\hline
\end{tabular}

من خلال الجدول أعلاه، يلاحظ أن المتوسطات الحسابية لاستجابات أفراد العينة، لدرجة

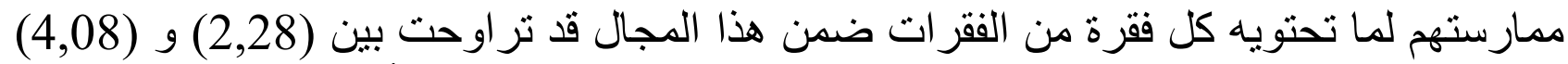

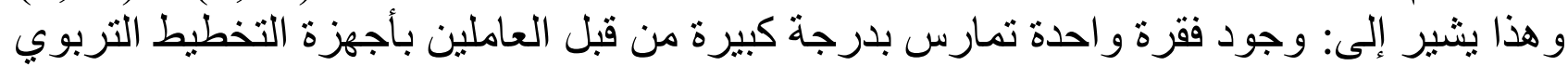

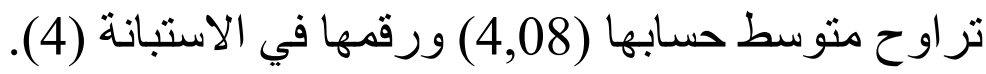

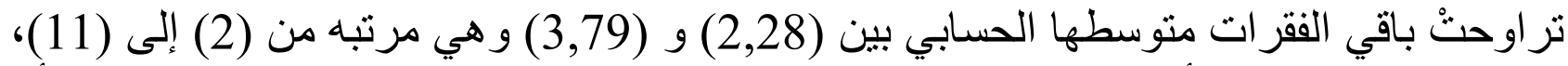

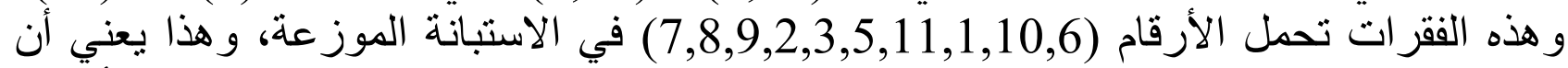
العمليات التخطيطية المتمثلة بهذه الفقرات تمارس بلفئة بدرجة منوسطة من قبل العاملين بأجهزة التخطيط من وجهة نظر أفر اد العينة. ويلاحظ أن الفقرتين رقم (5) و (3) حصلتا على الرنبة (6) نفسها، وهذا يعني فئي أن العمليات

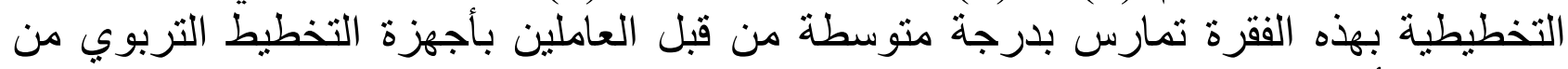
وجهة نظر أفراد العينة.

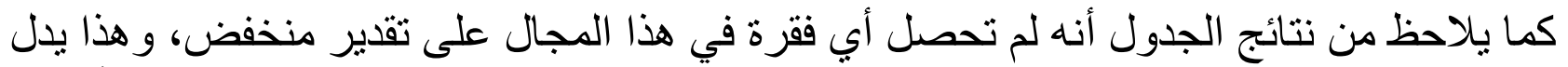

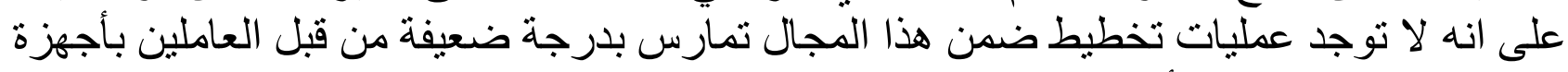
التخطيط من وجهة نظر أفر اد العينة.

الكوادر التخطيطية

يبين الجدول رقم (6) المتوسطات لحسابية والانحر افات المعيارية والأهمية النسبية (الرتبة)

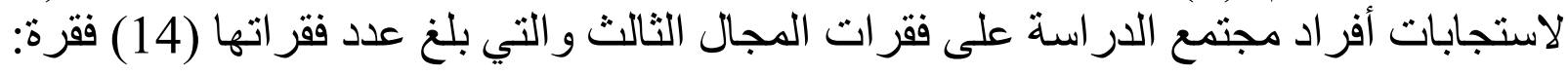
جدول (6) تقدير ات أفر اد عينة الدراسة مجتمعه على فقرات الكو ادر التخطيطية

\begin{tabular}{|c|c|c|c|c|c|}
\hline الممارجة & المعياري & الحستوسي & الفقرة & $\overline{3}$ & تلفقرة \\
\hline متوسطة & 0.88 & 3,91 & يلم العاملون بالتقنيات التخطيطية اللازمة & 1 & 3 \\
\hline
\end{tabular}


IJASOS- International E-Journal of Advances in Social Sciences, Vol. VI, Issue 17, August 2020

\begin{tabular}{|c|c|c|c|c|c|}
\hline متوسطة & 0,61 & 3,86 & التوقتخات المستقطلية برن امج حديثة في حساب & 2 & 4 \\
\hline متوسطة & 0.81 & 3,74 & يتم تدريب المخططين التربوبين أثناء الخدمة & 3 & 5 \\
\hline متوسطة & 0,92 & 3,61 & يندر الاختصاصيون في التخطيط التربوي & 4 & 6 \\
\hline متوسطة & 0,73 & 3,56 & المعنية بالتخطيط المخطون في المؤتمر ات و الندو ات & 5 & 11 \\
\hline متوسطة & 0,84 & 3,52 & التربوية المناحة المطون القدرة على تفسير البيانات & 6 & 14 \\
\hline متوسطة & 0,79 & 3,48 & يتم تعيين العاملين بالتخطيط على أسس موضو عية & 7 & 13 \\
\hline متوسطة & 0,84 & 3,46 & يتمتع المخططون بالكفاءة الفنية اللازمة & 8 & 10 \\
\hline متوسطة & 0,91 & 3,41 & يتميز العاملون في التخطيط بالقدرة على الإبداع & 9 & 2 \\
\hline متوسطة & 0,86 & 3,34 & تتوفر عناصر الخبرة في المخططين التربويين & 10 & 1 \\
\hline متوسطة & 0,82 & 3,21 & اللازتلك المخطن للتنبؤ مهون مهار ات الإدر الك و التصور & 11 & 8 \\
\hline متوسطة & 0,94 & 3,16 & تتمتع بر امج تدريب المخططين بقوة المحتوى & 12 & 12 \\
\hline متوسطة & 0,90 & 2,97 & متخولى عملية وضع الخطط التربوية مخططون & 13 & 7 \\
\hline متوسطة & 0.76 & 2,76 & القراللك العاملون في التخطبط القدرة على اتخاذ & 14 & 9 \\
\hline
\end{tabular}

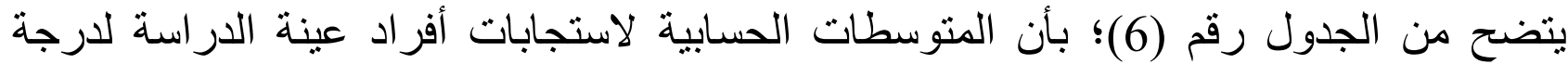

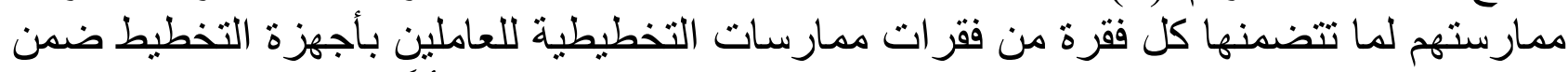

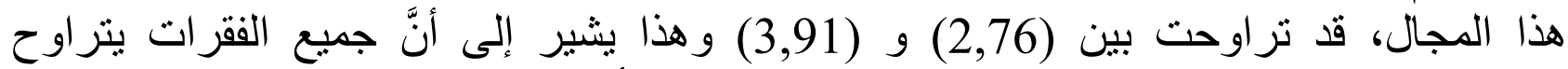

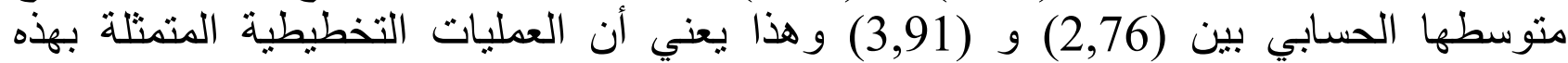
الفقرات تمارس بدرجة متوسطة من قبل العاملين بأجهزة التخطيط التربوي أني من وجهة نظر أفراد العينة.

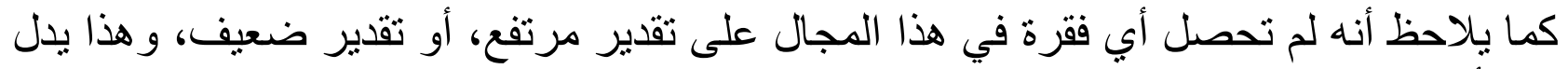

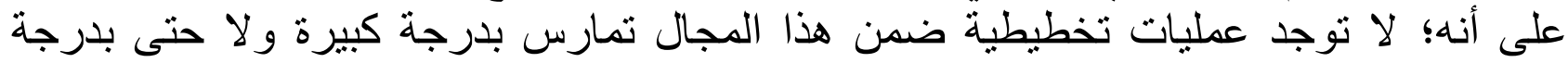

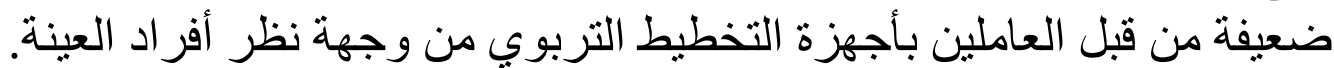
المعلومات التربوية:

يبين الجدول رقم (7) المنوسطات لحسابية والانحر افات المعيارية والأهمية النسبية (الرنبة)

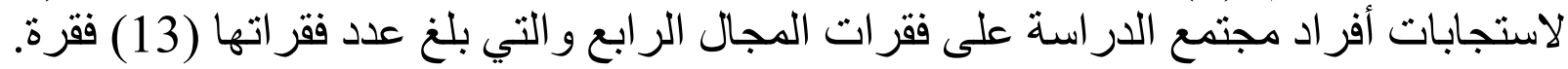
جدول (7) تقدير ات أفر اد عينة الدر اسة مجتمعه على فقر ات المعلومات التربوية

\begin{tabular}{|c|c|c|c|c|c|}
\hline الممارجة & المعياري & الحستوسي & 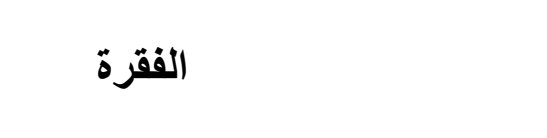 & 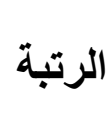 & تلفقلسل \\
\hline 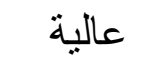 & 0.88 & 4,21 & يتم تنظيم وتبويب البيانات التربوية & 1 & 5 \\
\hline
\end{tabular}


IJASOS- International E-Journal of Advances in Social Sciences, Vol. VI, Issue 17, August 2020

\begin{tabular}{|c|c|c|c|c|c|}
\hline 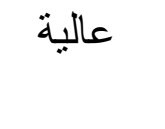 & 0,93 & 4,01 & جمع وحفظ البيانات عن أعداد الطلاب ومعدلات & 2 & 6 \\
\hline متوسطة & 0,81 & 3,93 & تشكلية نظوري المعلومات التربوية بالبيانات والإحصائية & 3 & 1 \\
\hline 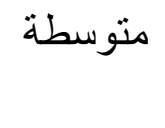 & 0.98 & 3,86 & ومواقعها وحفظ البيانات الإحصائية عن أعداد المدارس & 4 & 4 \\
\hline 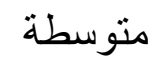 & 0,69 & 3.76 & يتم إدارة المعلومات وفق نظام محدد & 5 & 7 \\
\hline متوسطة & 0,83 & 3,66 & التخطيط التربوي و الأدلة والمويات عن المستجدات الحديثة في & 6 & 11 \\
\hline متوسطة & 0,94 & 3.66 & تتوفر الإحصاءات المتعلقة بخطط ومشاريع التنمية & 6 & 13 \\
\hline 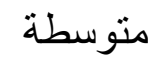 & 0.84 & 3.51 & تتوفر البيانات و الإحصاءات قبل وقت كاف & 7 & 2 \\
\hline متوسطة & 0,91 & 3,46 & الأعوام إلقادمةاءت بأعداد الذين سيلتحقون بالتعليم في & 8 & 9 \\
\hline متوسطة & 0,89 & 3,38 & إلى الوز الإرة بسهاءات التربوية من المحافظات التعليمية & 9 & 10 \\
\hline 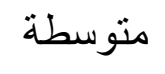 & 0,97 & 3,22 & تتصف الإحصاءات التربوية المتوفرة بالدقة & 10 & 3 \\
\hline متوسطة & 0,86 & 3,08 & في الدول البيانات التربوية المختلفة عن النظم التربوية & 11 & 12 \\
\hline متوسطة & 0,91 & 2,71 & التخطر الإحصاءات السكانية اللازمة لعمليات & 12 & 8 \\
\hline
\end{tabular}

ن خلال الجدول رقم (7) نشير النتائج إلى ما يلي: توجد فقرتان متوسطهما الحسابي (4,01) و

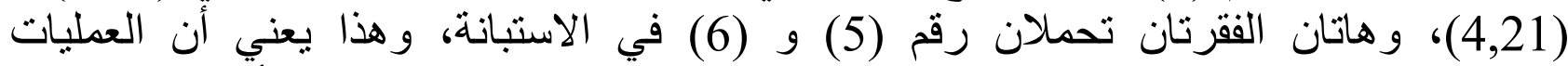
التخطيطية المتمثلة بهاتين الفقرتين تمارس بدرجة كبين كبيرة من قبل العبن العاملين بأجهزة التخطيط التربوي من وجهة نظر أفراد العينة.

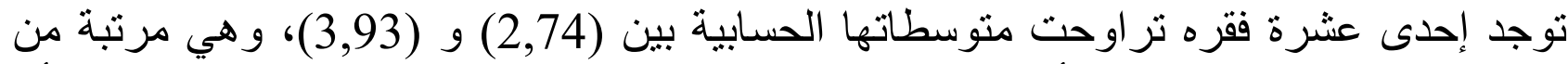

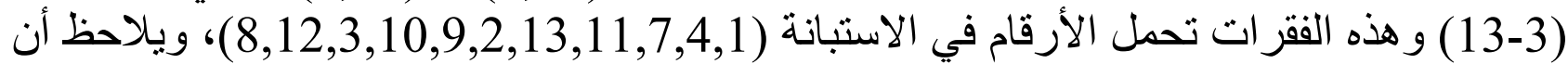

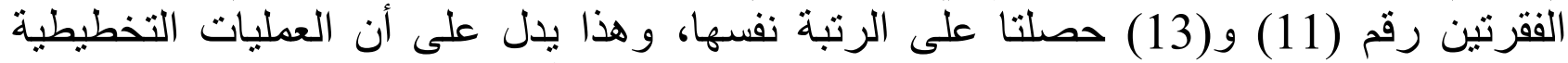

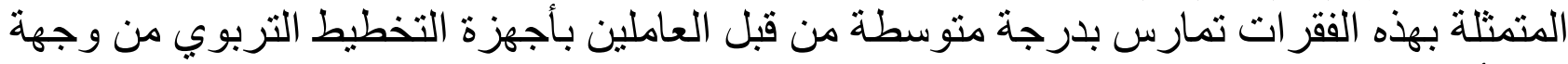

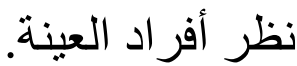




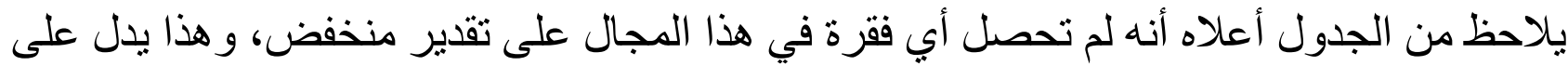

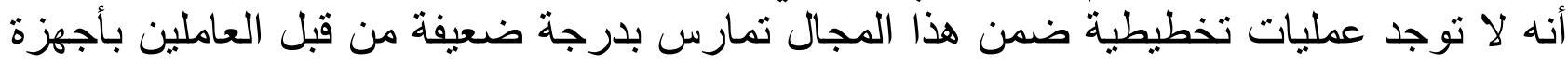
التخطيط التربوي من وجهة نظر أفراد عينة الدر اسة.

مناقشة النتائَج:

بعد حساب متوسطات تقدير ات أفراد العينة حول واقع ممارساتهم التخطيطية بأجهزة التخطيط

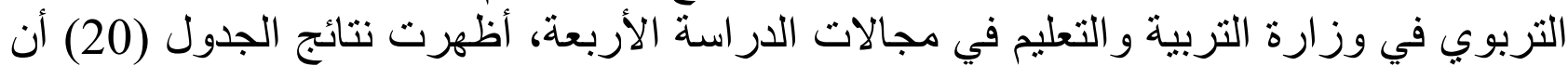

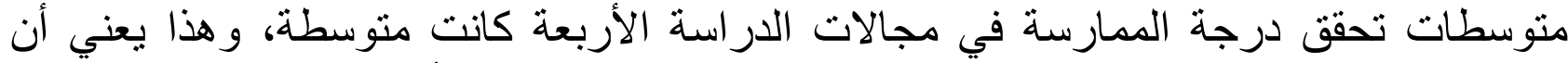

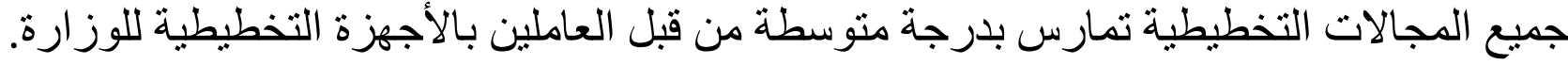

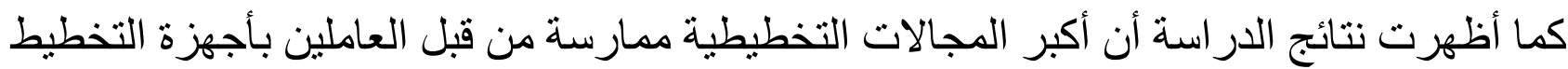

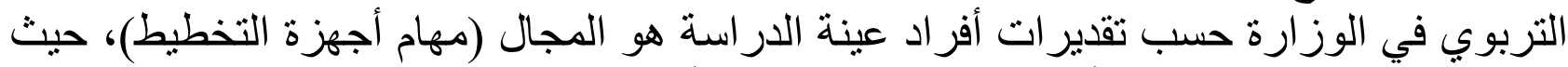

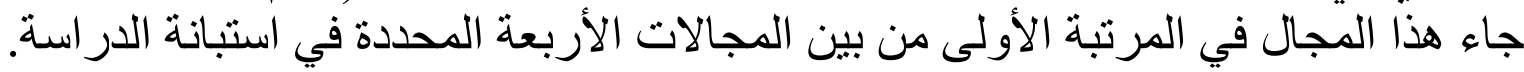

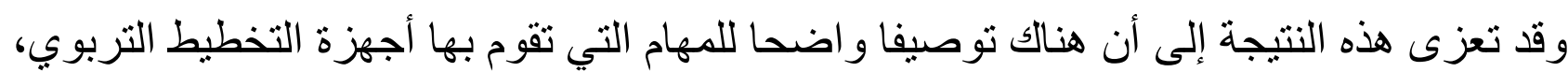

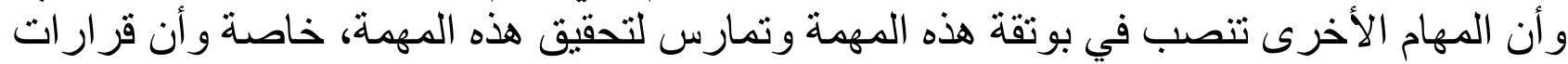

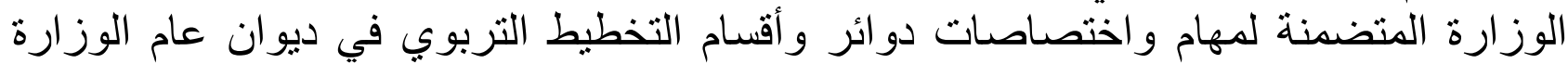

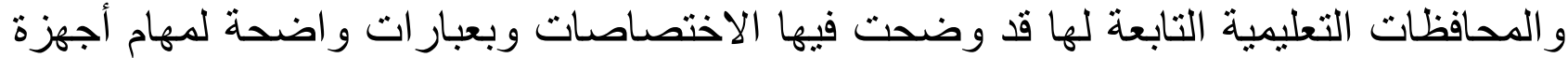

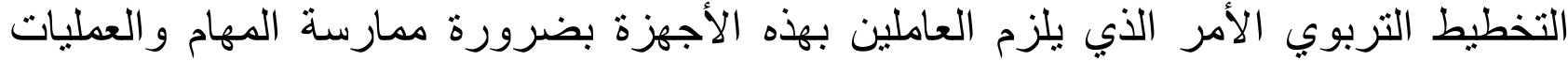

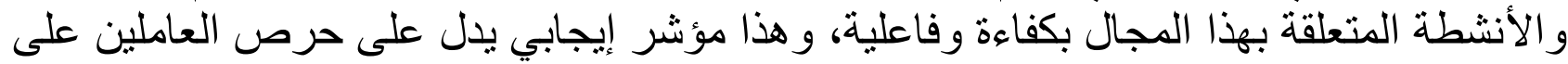

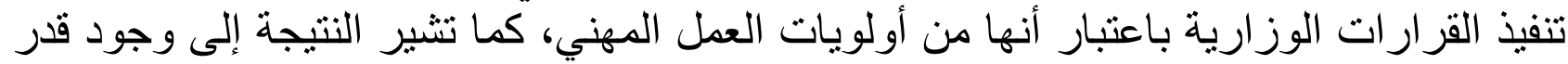

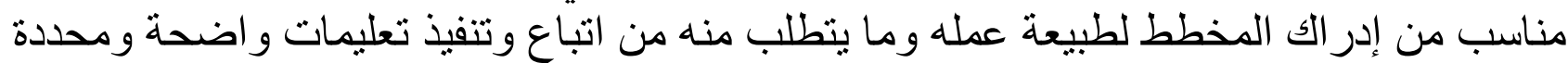

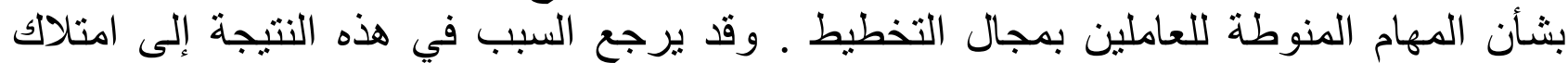

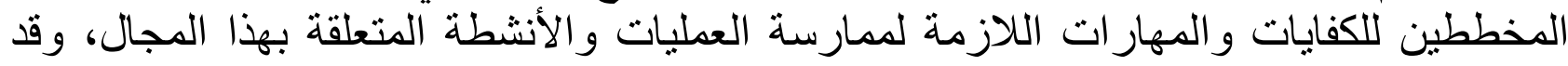

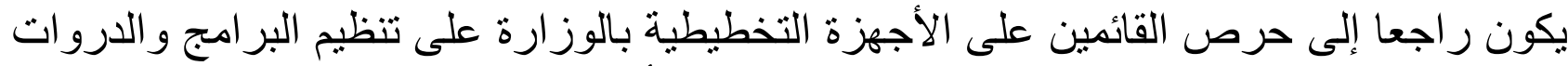

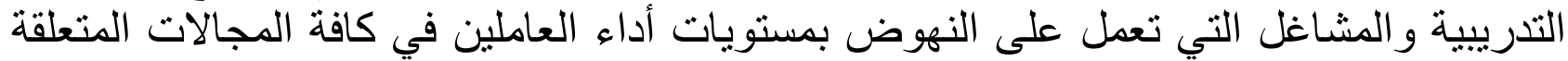

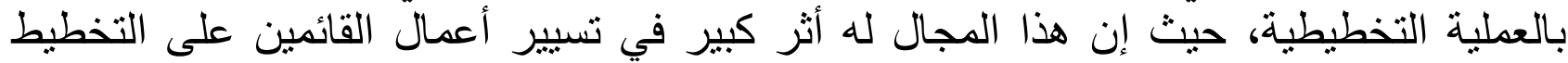

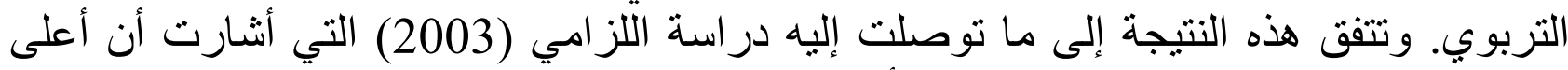

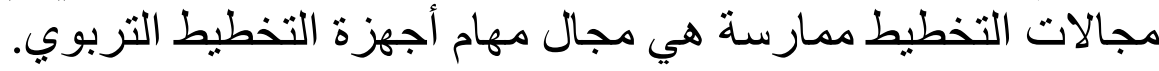

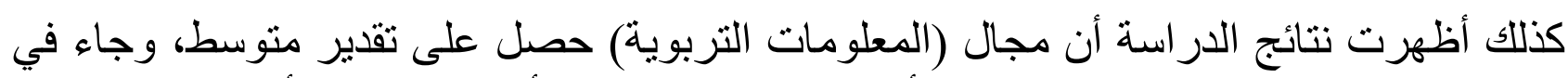
الرنبة الثانية ضمن مجالات الدراسة الأربعة. وهذا يدل على الثلى أن العاملين بالأجهزة التخطيطية

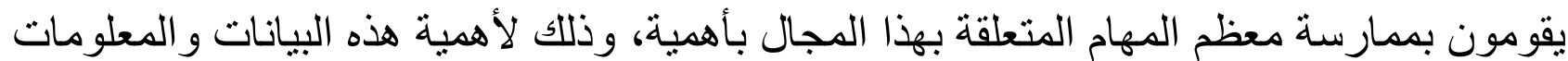

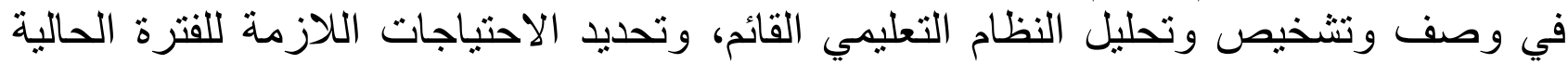

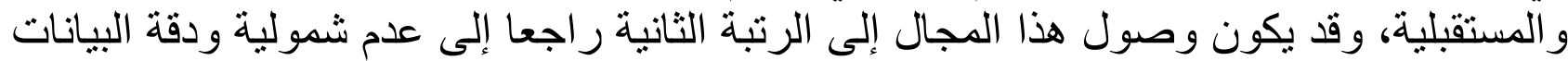

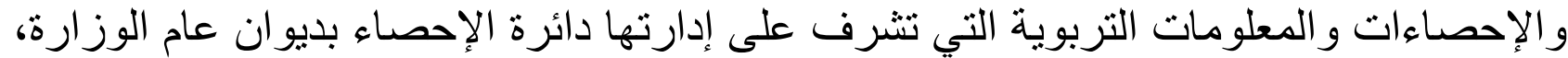

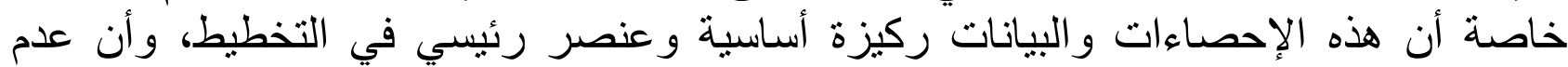

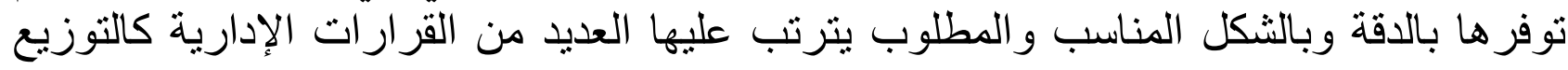
غير العادل للخدمات التعليمية. 
كذلك من أسباب حصول هذا المجال على الرتبة الثانية مقارنة بالمجال الأول؛ تكليف المخططين

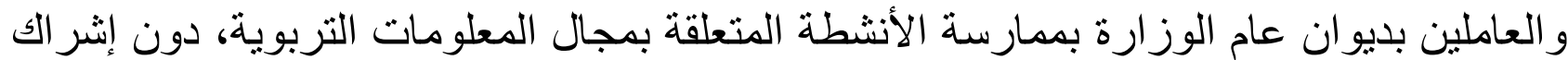
العاملين بقسم الإحصاء بالمحافظات التعليمية بممارستها، على الرغم من در ايتهم ومعرفتهم بواقع دون مديرياتهم.

كذلك أظهرت نتائج الدراسة أن مجال ( الكو ادر التخطيطية) قد حصل على تقدير متوسط ، وجاء في المرتبة الثالثة من ضدن مجالات الدراسة الأربعة، وهذا بدل على أن العمليات و المهام و الأنشطة المتعلقة بهذا المجال تمارس بدرجة أقل مقارنة بالمجالين السابقين، وذلك قد يرجع إلى ولى الى

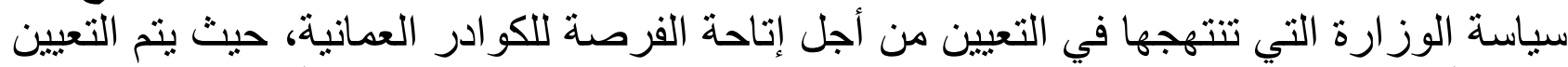
بهذه الأجهزة كو ادر علمية ولكنها غير متخصصة في الجانب التخطيطية، كما أنه لا توجد مر اكز تدريب ومعاهد متخصصة تعمل على تخريج كو ادر متخصصة في جو انب التخطيط . و وكذللك قد

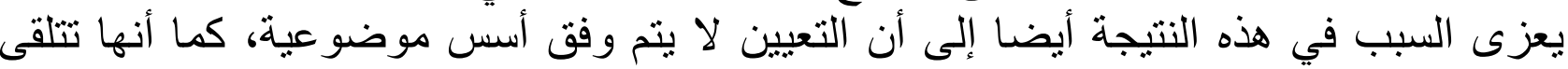
بر امج تدريب ضعيفة المحتوى. وتثفق هذه النتيجة مع ما توصلت إليه در اسة الحداد (1992) التي

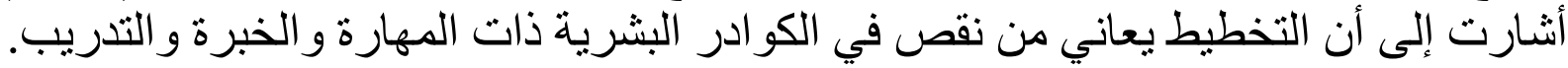
كما تتفق أيضا مع در اسة الحجاز (2002) التي أثارت إلى أن التخطيط يعاني من مشاكل عديدة،

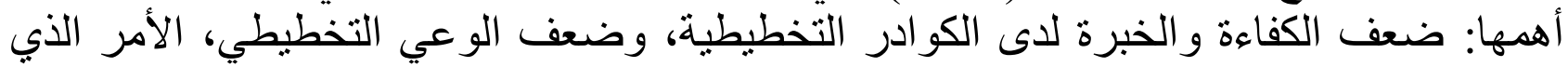
يستدعي ضرورة الاهتمام بتدريب العاملين على ممارسة الكفايات التخطيطية. كما قد يعود السبب في هذه النتيجة إلى تكليف العاملين بأجهزة التخطيط بأعمال إدارية تعوق مهامهم الأصلية. كما أظهرت نتائج الدراسة أن مجال (التظيم الإداري) قد حصل على تقدير متوسط، وجاء في المرتبة الأخيرة ضمن مجالات الدراسة الأربعة، وهذا بدل على أن العمليات والأنشطة المتعلقة

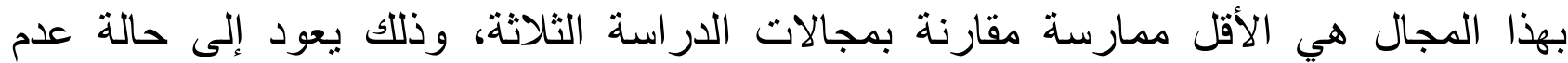
الاستقرار التنظيمي في هذه الأجهزة نتيجة كثرة التعديلات و التغيرات التي تطرأ على الهيكل التنظيمي للوزارة وما يترنب عليه من دمج للأقسام أو فصلها، وتغة ونغيير في مسمياتها ومسميات

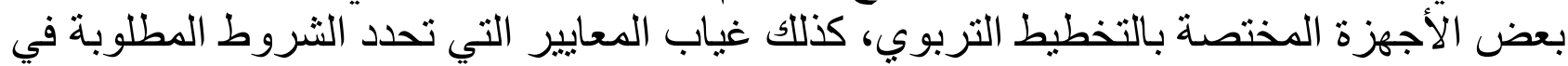

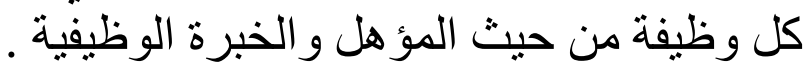
تكتب المراجع بدون أرقام. كما في النماذج الثلاث الأولى. تحذف جميع المراجع الزائدة في القائمة: غير الواردة في المقال

قائمة المر اجع: أحمد، ماهر. (1996). دليل المدير خطوة بخطوة في مجال الإدارة الإستر اتيجية. الإسكندرية: الدار الجامعية. ماه.

حجي، أحمد إسماعيل. (1992). دراسة تقويمية لتخطيط التعليم في مصر وخطة إصلاح نظامه،

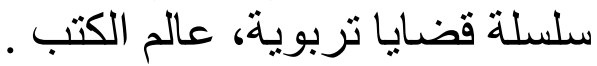

حجي، أحمد إسماعيل. (2002). اقتصاديات التربية والتخطيط التربوي، القاهرة: دار الفكر العربي. 
الحوسني, حمحـ شامس. (2008). بناء انموذج للتخطيط الاستر اتيجي لوز ارة التربية و التعليم بسلطنة

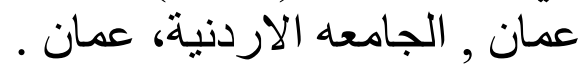

الخروص، عبدالله حميد. (2001). دراسة تقويمية لنظام إدارة المعلومات التربوية بوزارة التربية

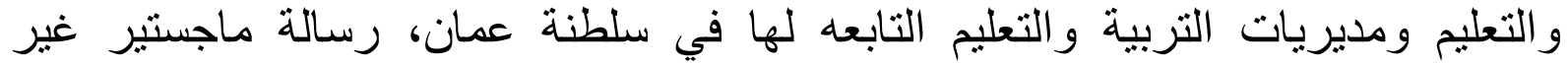

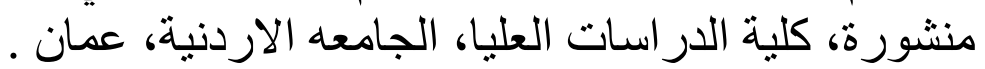

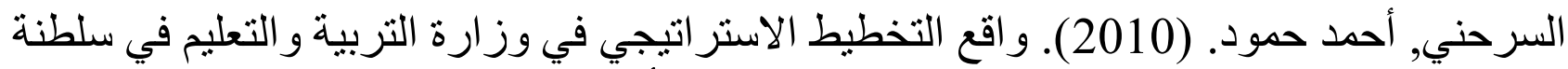
عمان من وجهة نظر المديرين ، جامة اليرموك النيط ، الأردن .

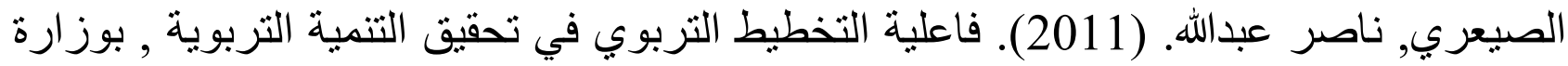

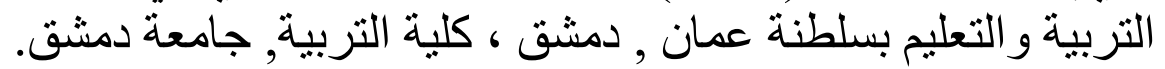

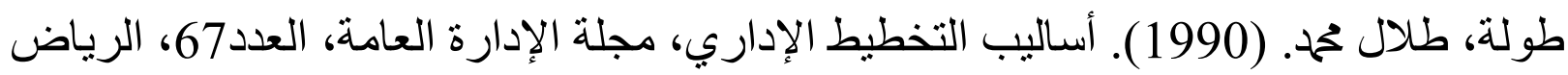
غيداء، عبدالله. (2007):مشكلات التخطيط التربوي لدى مديري المدارس الحكومة في فلسطين. دولة فلسطين.

الكردي، رنا داؤود. (2010). درجة تطبيق التخطبط الاستراتيجي في مديريات التربية و التعليم الضفة الغربية من وجهة نظر العاملين فيها, نابلس، جامة النجاح النجاح الوطنية ، فلسطين .

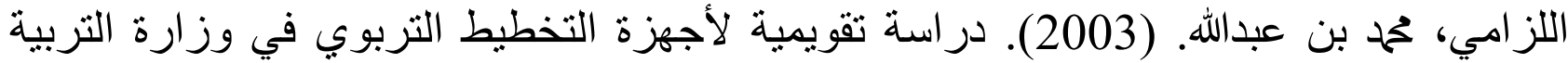

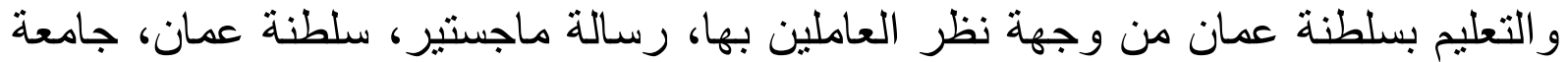
السلطان قابوس.

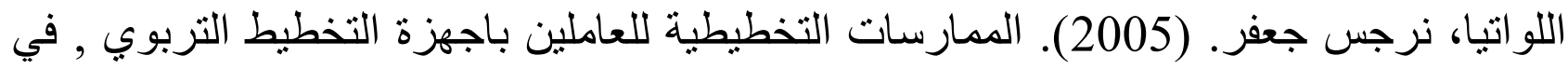

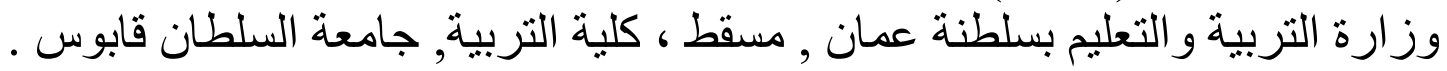

مطاوع، إبر اهيم. (2003). الإدارة التربوية في الوطن العربي، القاهرة: دار الفكر للطباعهاهو النشر والتوزيع.

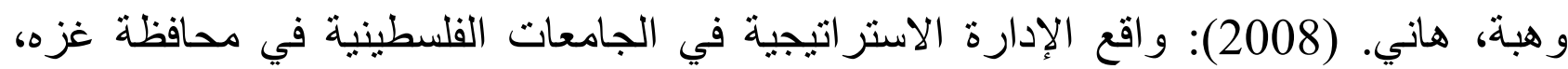

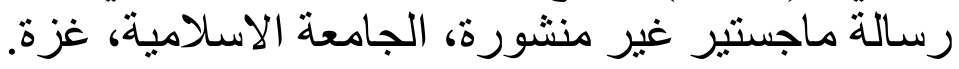

\section{ARABIC REFERENCES IN ROMAN ALPHABET}

'Ahmad, Mahur. (1996). Dalil Almudir Khatwatan Bikhatwat fi Majal Al'iidarat Al'iistiratijiati. Al'iiskandariata: Aldaar Aljamieiat.

Haji, 'Ahmad 'lismaeil. (1992). Dirasatan Taqwimiatan Litakhtit Altaelim fi Misr Wakhutat 'lislah Nizamihi, Silsilat Qadaya Tarbwiat, Ealam Alkutub.

Hujy, 'Ahmad 'lismaeil. (2002). Aiqtisadiaat Altarbiat Waltakhtit Altrbwy, Alqahrt: Dar Alfikr Alearabi.

Alhwsny, Muhamad Shams. (2008). Bina' Anmwdhj Liltakhtit Al'iistratiji Liwizarat Altarbiat Waltaelim Bisaltanat Eamman, Aljamieih Alardiniti, Eamman .

Alkhurusu, Eabdallh Hmyd. (2001). Dirasatan Taqwimiatan Linizam 'lidarat Almaelumat Altarbawiat Biwizarat Altarbiat Waltaelim Wamudiriat Altarbiat Waltaelim Alttabieih Laha fi Saltanat Eammana, Risalat Majstyr Ghyr Manshurati, Kuliyat Aldirasat Aleulya, Aljamieih Alardinyt, Eamman.

Alsarahani, 'Ahmad Humwd. (2010). Waqie Altakhtit Al'iistratiji fi Wizarat Altarbiat Waltaelimf fi Saltanat 
Eamman Min Wijhat Nazar Almudirin, Jamat Alyarmuk, Al'urduni .

Alsiyeri, Nasir Eibdalluh. (2011). Faeiliat Altakhtit Altarbawii fi Tahqiq Altanmiat Altarbawiat, Biwizarat Altarbiat Waltaelim Bisiltanat Eamman, Dimashq, Kuliyat Altarbiat, Jamieat Dimashq.

Tulatu, Talal Mhmd. (1990). 'Asalib Altakhtit Al'iidari, Majalat Al'iidarat Aleamat, Aledd67, Alriyad

Ghayda'u, Eabdalluh. (2007):Mushkulat Altakhtit Altarbawii Ladaa Mudiri Almadaris Alhukumat fi Filastin. Dawlat Filastin.

Alkirdiu, Rana Dawwd. (2010). Darajat Tatbiq Altakhtit Al'iistratijii fi Mudiriat Altarbiat Waltaelim Aldifat Algharbiat Min Wijhat Nazar Aleamilin Fyha, Nablus, Jamat Alnajah Alwataniat, Filastin .

Allizamiu, Muhamad Bin Eabdallah. (2003). Dirasatan Taqwimiatan Li'ajhizat Altakhtit Altarbawii fi Wizarat Altarbiat Waltaelim Bisiltanat Eamman Min Wijhat Nazar Aleamilin Biha, Risalat Majstir, Saltanat Euman, Jamieat Alsultan Qabus.

Alluwatia, Nurjis Jefr. (2005). Almumarasat Altakhtitiat Lileamilin Bi'ajhizat Altakhtit Altarbuii , fi Wizarat Altarbiat Waltaelim Bisaltanat Eamman , Masqat , Kuliyat Altrbyt, Jamieat Alsultan Qabws .

Matawie, 'librahim. (2003). Al'iidarat Altarbawiat fi Alwatan Alearbii, Alqahrt: Dar Alfikr Liltibaeih Walnashr Waltawzie.

Wahibati, Hani. (2008): Waqie Al'iidarat Al'iistiratijiat fi Aljamieat Alfilastiniat fi Muhafazat Ghazihi, Risalat Majsatayr Ghyr Minshurat, Aljamieat Alaislamiati, Ghazat.

\section{REFERENCES}

Steadham, k.s. (2006). strategic management competencies among chief human resource officers in Texas public colleges. Ed.D. Texas A\&M University - Commerce. 